University of Louisville

ThinkIR: The University of Louisville's Institutional Repository

$5-2015$

\title{
Analysis of anacardic acid on the surface of Pelargonium $x$ hortorum using matrix assisted laser desorptoin ionization mass spectrometry imaging.
}

Bryan Edward Wessel 1989-

University of Louisville

Follow this and additional works at: https://ir.library.louisville.edu/etd

Part of the Chemistry Commons

\section{Recommended Citation}

Wessel, Bryan Edward 1989-, "Analysis of anacardic acid on the surface of Pelargonium $\times$ hortorum using matrix assisted laser desorptoin ionization mass spectrometry imaging." (2015). Electronic Theses and Dissertations. Paper 2146.

https://doi.org/10.18297/etd/2146

This Master's Thesis is brought to you for free and open access by ThinkIR: The University of Louisville's Institutional Repository. It has been accepted for inclusion in Electronic Theses and Dissertations by an authorized administrator of ThinkIR: The University of Louisville's Institutional Repository. This title appears here courtesy of the author, who has retained all other copyrights. For more information, please contact thinkir@louisville.edu. 


\title{
ANALYSIS OF ANACARDIC ACID ON THE SURFACE OF Pelargonium $x$ hortorum USING MATRIX ASSISTED LASER DESORPTOIN IONIZATION MASS SPECTROMETRY IMAGING
}

\author{
By
}

\section{Bryan Edward Wessel}

B.S., University of Louisville 2011

M.S., University of Louisville 2015

M.B.A, University of Louisville 2015

\author{
A Thesis \\ Submitted to the Faculty of the \\ College of Arts and Sciences of the University of Louisville \\ in Partial Fulfillment of the Requirements \\ for the Degree of
}

Master of Science in Chemistry

Department of Chemistry

University of Louisville

Louisville, Kentucky

May 2015 
Copyright 2015 by Bryan Edward Wessel

All rights reserved 



\title{
ANALYSIS OF ANACARDIC ACID ON THE SURFACE OF Pelargoniumx hortorum USING MATRIX ASSISTED LASER DESORPTOIN IONIZATION MASS SPECTROMETRY IMAGING \\ By
}

\author{
Bryan Edward Wessel
}

B.S., University of Louisville 2011

M.S., University of Louisville 2015

A Thesis Approved on

April 10, 2015

by the following Thesis Committee:

Dr. M. Cecilia Yappert

Dr. Douglas B. Borchman

Dr. Francis P. Zamborini 


\section{DEDICATION}

I would like to dedicate my thesis work to my friends and family. First, I would like to especially thank my parents for their continual love and support; may this work be a signal of your success as parents.

I would also like to especially thank my fiancé, Kelly Ann Beglin, for her patience and support when things seemed the toughest. I know I can always count on her to laugh at my jokes and push me to be a better person in all aspects of life. Also, I would like to thank all of my siblings (Matt, Jamie, and Mackenzie) and their spouses (Amanda and Brandon) and my nieces (Evie, Ada, and Charlie, and those to come) for the overwhelming joy they have brought to my life and congratulate them on all of their successes in life.

I also dedicate this work to Mrs. Nieport (Leslie) and her family. You guys continually go out of your way to ensure that I am successful in both school and life. To Mrs. Nieport, I hope this works shows the difference you make in students' lives even when others aren't believing in them.

Last and certainly not least, I would like to thank God for the undeserving success he has bestowed upon me; to you, I am forever indebted. 


\section{ACKNOWLEDGEMENTS}

I would like to thank my advisor, Dr. M. Cecilia Yappert, for all of her guidance and support. I would also like to thank my committee members, Dr. F.P. Zamborini and Dr. D.B. Borchman, for their advice and assistance over the past three years. Finally, I would like to thank Dr. Schultz for his support as both and undergraduate and graduate student. 


\begin{abstract}
ANALYSIS OF ANACARDIC ACID ON THE SURFACE OF Pelargonium $x$ hortorum USING MATRIX ASSISTED LASER DESORPTOIN IONIZATION MASS SPECTROMETRY IMAGING

Bryan E. Wessel
\end{abstract}

April 10, 2015

The biosynthetic pathway leading to the production of anacardic acids (AnAcs) in glandular trichomes on the surface of geranium plants remains unclear. Anacardic acids are salicylic acid derivatives known to possess various medicinal benefits. Gene silencing techniques, such as RNA interference, could be useful in determining specific enzymes involved in the synthesis of AnAcs. However, it is first necessary to develop methodologies to image AnAcs. In this project, both fluorescence (FL) and mass spectral imaging (MSI) were tested. Our results indicate that cellular imaging of AnAcs, via FL, is not suitable because the spectral ranges of absorption and emission of AnAcs fall within the same range of common cellular components. Furthermore, FL cannot distinguish among various AnAcs. Fortunately, and with the use of a new and stable matrix, bis(p-nitrophenly) amine, in-situ imaging of AnAcs using MALDIMSI has been achieved for the first time. 


\section{TABLE OF CONTENTS}

Page

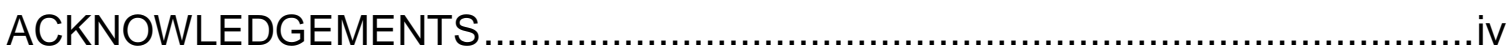

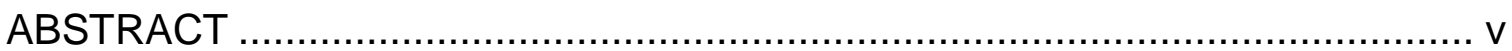

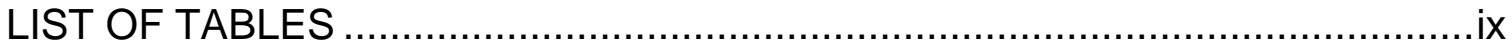

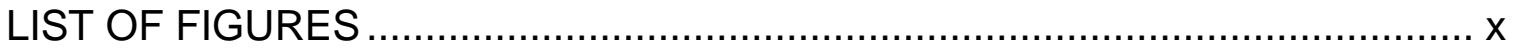

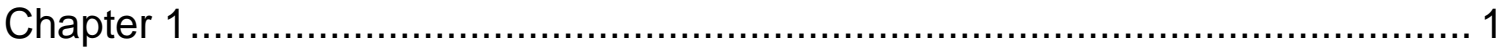

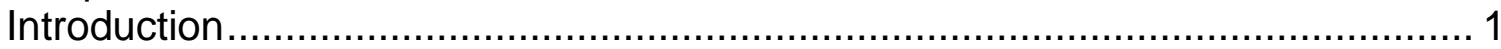

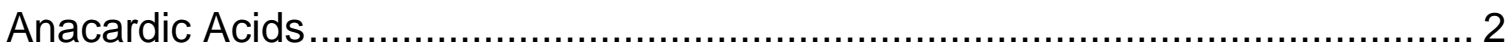

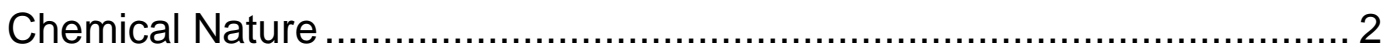

Presence in Biological Tissues ..................................................... 4

Potential Use as Therapeutic Agents.................................................. 4

Analysis of Anacardic Acids ................................................................ 5

Molecular Fluorescence (FL) Spectroscopy ……................................ 8

Physical Principles and Basic Instrumentation .............................. 8

Previous Studies of Anacardic Acids by FL................................ 12

Tissue Imaging by FL Spectroscopy: Advantages and

Disadvantages ................................................................... 12

Mass Spectrometry (MS) ........................................................... 13

Physical Principles and Basic Instrumentation ............................ 13

Ionization Approaches 1....................................................... 4

ESI ........................................................................... 14

Matrix Assisted Laser Desorption Ionization (MALDI) ........ 16

Mass Analyzers................................................................. 21

Time-of-Flight (TOF) ................................................. 21

Previous Studies of Anacardic Acids by MS ............................. 24

Mass Spectrometry Imaging (MSI): Advantages/Disadvantages and

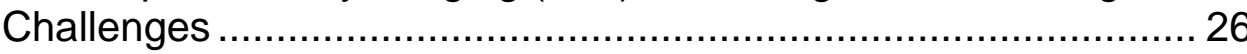

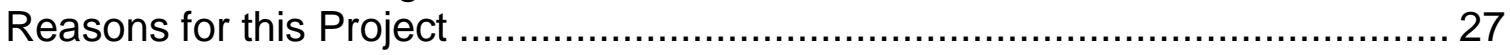

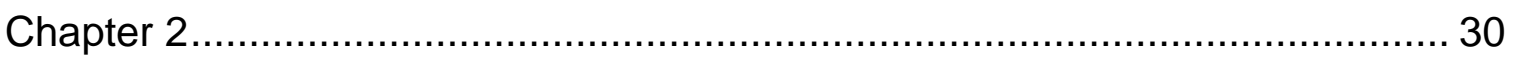

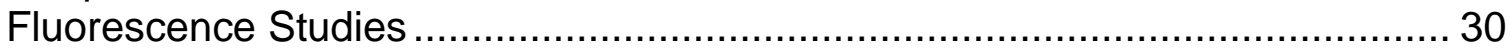

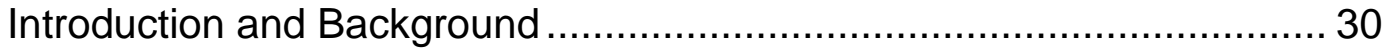

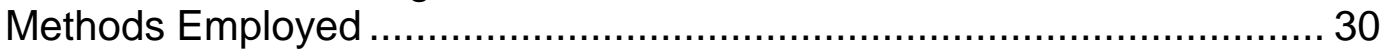

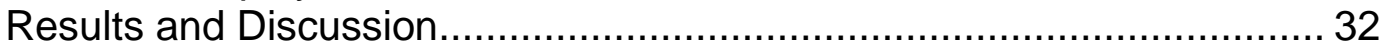

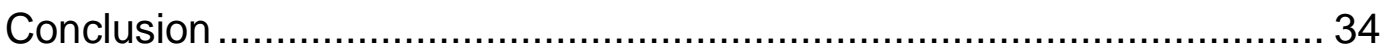

Matrix Assisted Laser Desorption Ionization Mass Spectrometry Imaging (MADLI-

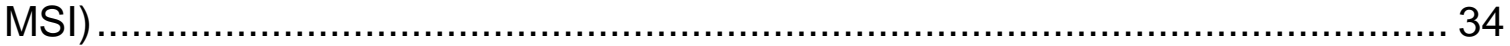




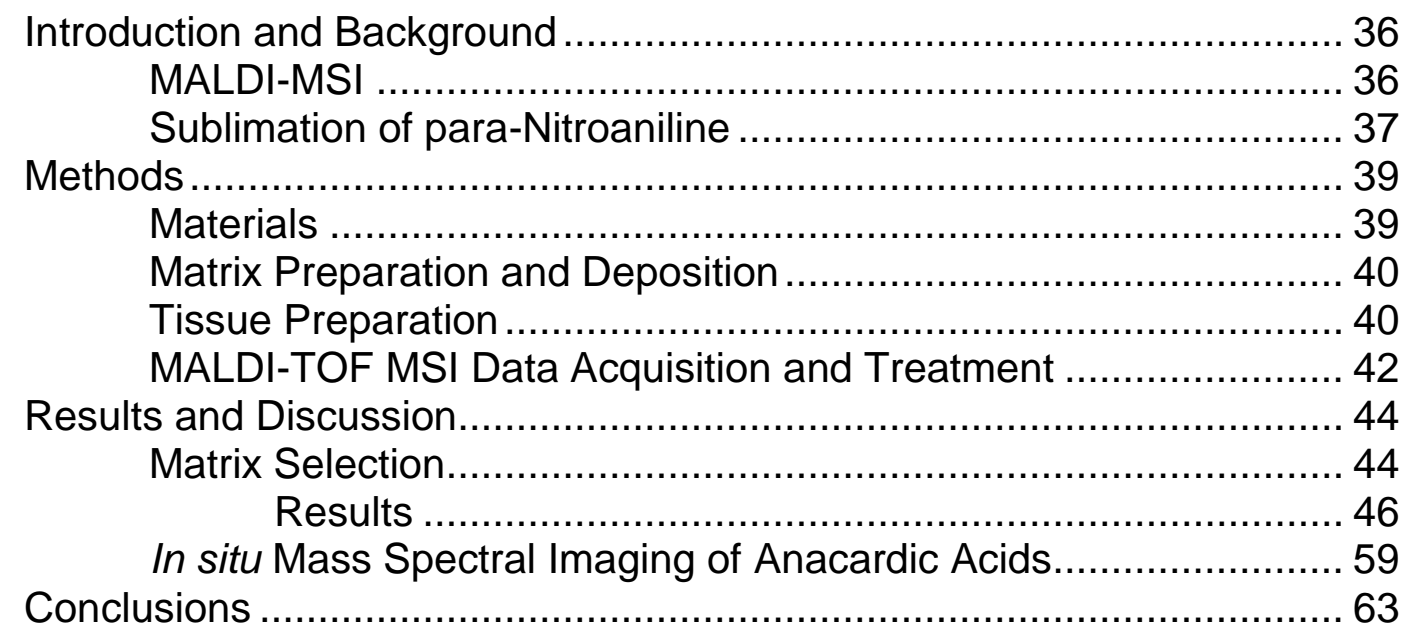

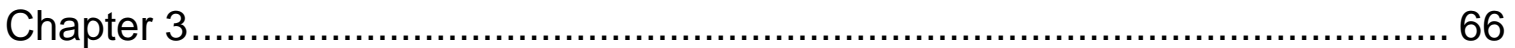

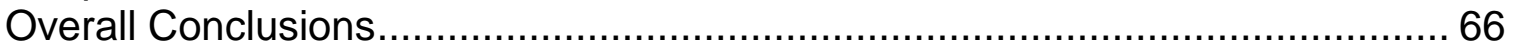

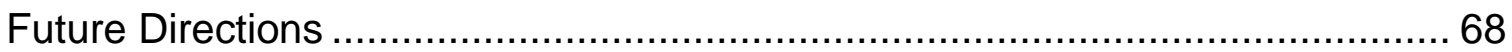

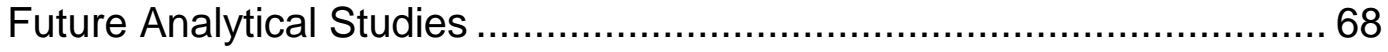

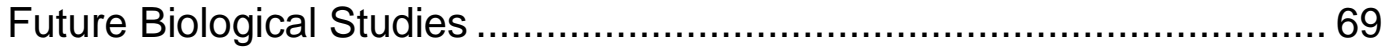

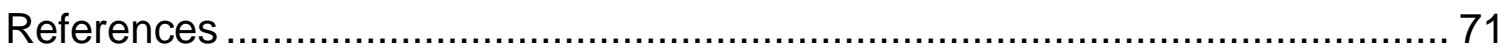

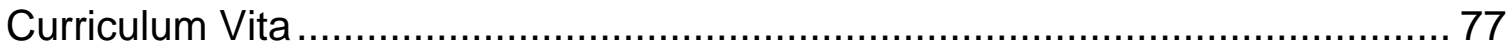




\section{LIST OF TABLES}

Table Page

1. Various pharmacological roles for different Anacardic Acids ......................... 6

2. Soft and hard ionization methods for mass spectrometry analysis ................ 15

3. Comparison of common mass analyzers ................................................... 22 


\section{LIST OF FIGURES}

Figure Page

1. Structures of Various Anacardic Acids ………........................................... 3

2. Jablonski Energy Diagram .................................................................... 9

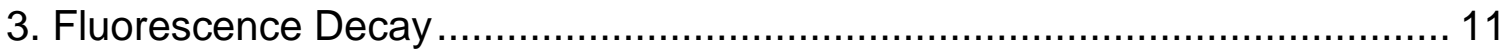

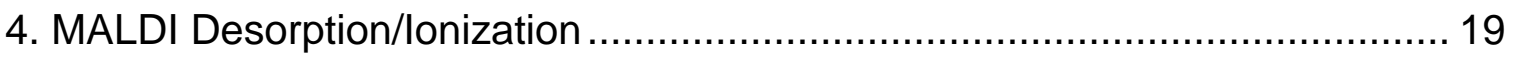

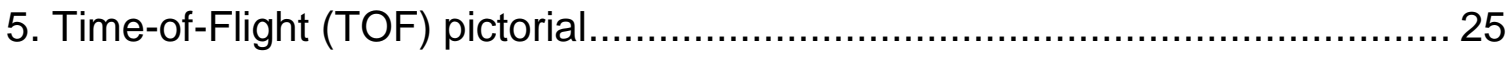

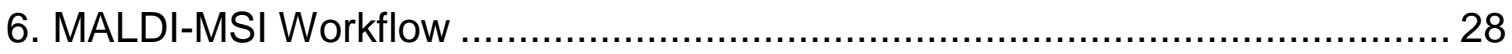

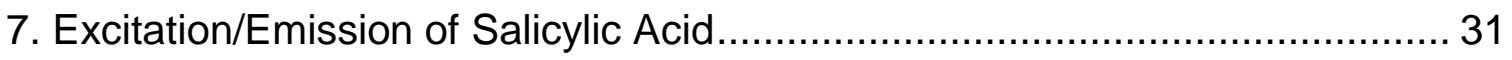

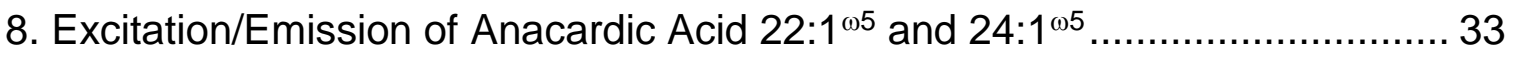

9. Excitation/Emission of Endogenous Fluorophores .................................... 35

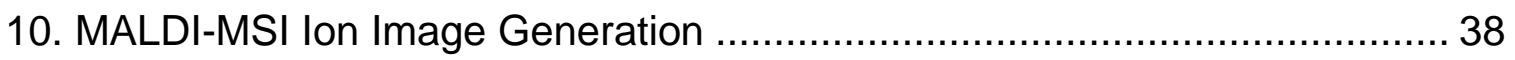

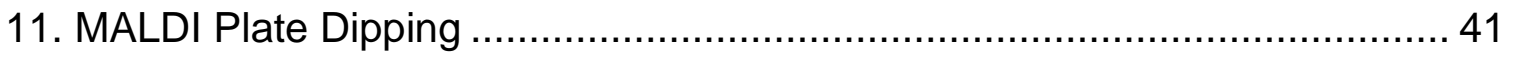

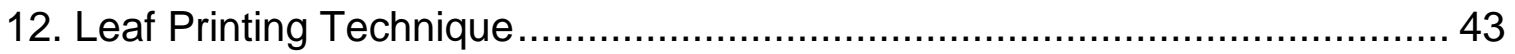

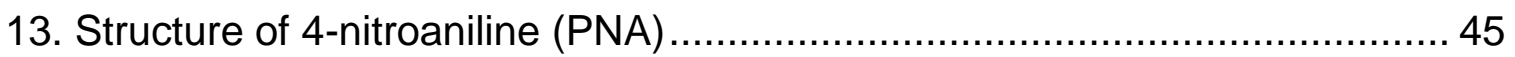

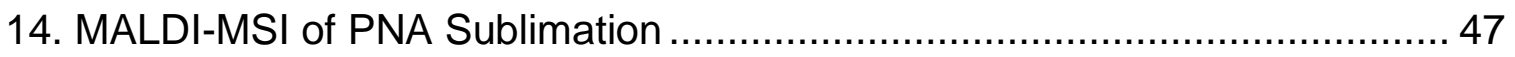

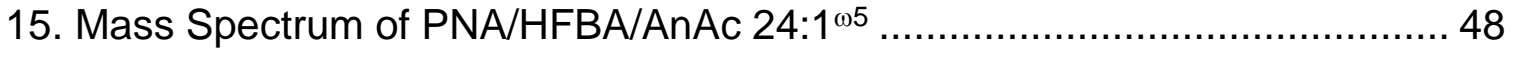

16. Structure of (3-aminopropyl)triethyoxysilane (APTES) …............................ 49

17. Structure of 2,5-dihydroxyacetophenone (2,5-DHA) ................................ 51

18. Mass Spectra of PNA Sublimation Process ................................................. 52

19. Structure of bis( $p$-nitrophenyl)amine (BNPA) ............................................ 54

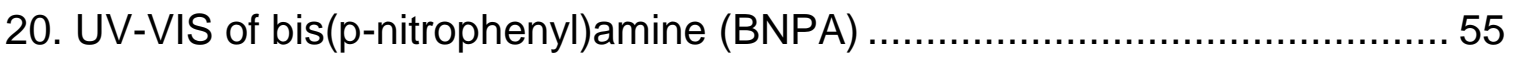

21. Mass Spectra of BNPA at Different Times........................................... 56/57

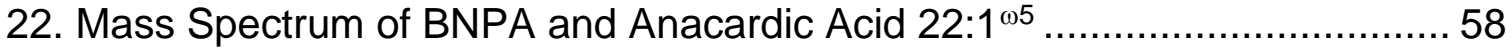

23. Leaf Image Experiment with Ion Image and Digital Image Overlay .............. 61 


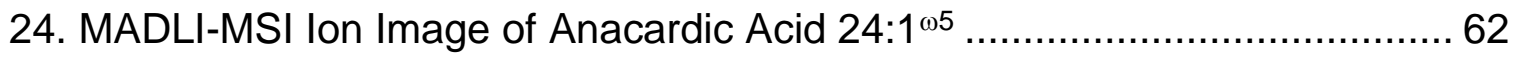

25. MALDI-MSI Ion Image of Unknown Geranium Leaves ................................ 64 


\section{CHAPTER 1}

In this chapter, the chemical nature of anacardic acids (AnAcs) and their potential as therapeutic agents will be introduced. Then the analytical methodologies applied for the detection of AnAcs will be discussed. In particular, molecular fluorescence spectroscopy and mass spectrometry will be described since these are the two methodologies used to conduct this project. A brief discussion of the physical principles and instrumentation employed by each of analytical techniques will be presented first. Then the advantages and disadvantages as well as the challenges of the application of these techniques for the imaging of biological systems will be addressed. Lastly, the reasons for this project, namely the development and optimization of approaches that enable the in-situ imaging of AnAcs, will be outlined.

\section{Introduction and Background}

Throughout human history, people have relied heavily on nature for food, shelter, clothes, and medicine. As indicated in Reference 1, "The first records, written on hundreds of clay tablets in cuneiform, are from Mesopotamia and date from about $2600 \mathrm{BC}$, amongst the approximately 1000 plant-derived substances which they used were oils Cedrus species (cedar) and Cupressus sempevirens (cypress), Glycyrrhiza glabra (licorice), Commiphora species (myrrh), and Papaver somniferum (poppy juice), all of which are still in use today for the 
treatment of ailments from coughs and colds to parasitic infections and inflammation" (Newman, Cragg, \& Snader, 2000). Although the use of plants as a medical therapy dates back to over 4,000 years ago, plant-derived compounds continue to play an important role in medicine.

In the 1980's, the World Health Organization (WHO) estimated that $80 \%$ of 400 million people still relied heavily on "traditional" medicine for their healthcare needs (Farnsworth, Akerele, Bingel, Soejarto, \& Guo, 1986). During this same time, plant- derived drugs played a vital role in medicine for developed countries. It was estimated that from 1959 to 1980, 25\% of prescription drugs dispensed in the United States were of plant origin, costing US consumers $\$ 8$ billion in 1980 alone (Farnsworth et al., 1986). However, by 1990, the $25 \%$ of plant-derived drugs dispensed in the US had accounted for $\$ 15.5$ billion dollars of pharmaceutical sales (Balick, 1996). Although synthetically derived compounds have provided people with a new arsenal of drugs for treating disease, it is crucial that the study of plant-derived substances as medicinal remedies not be abandoned.

\section{Anacardic Acids}

\section{Chemical Nature}

Anacardic acids are salicylic acid derivatives that contain an alkyl chain at the $6^{\text {th }}$ position of the benzoic ring. This alkyl chain varies in in length and degree of unsaturation (see Figure 1). 

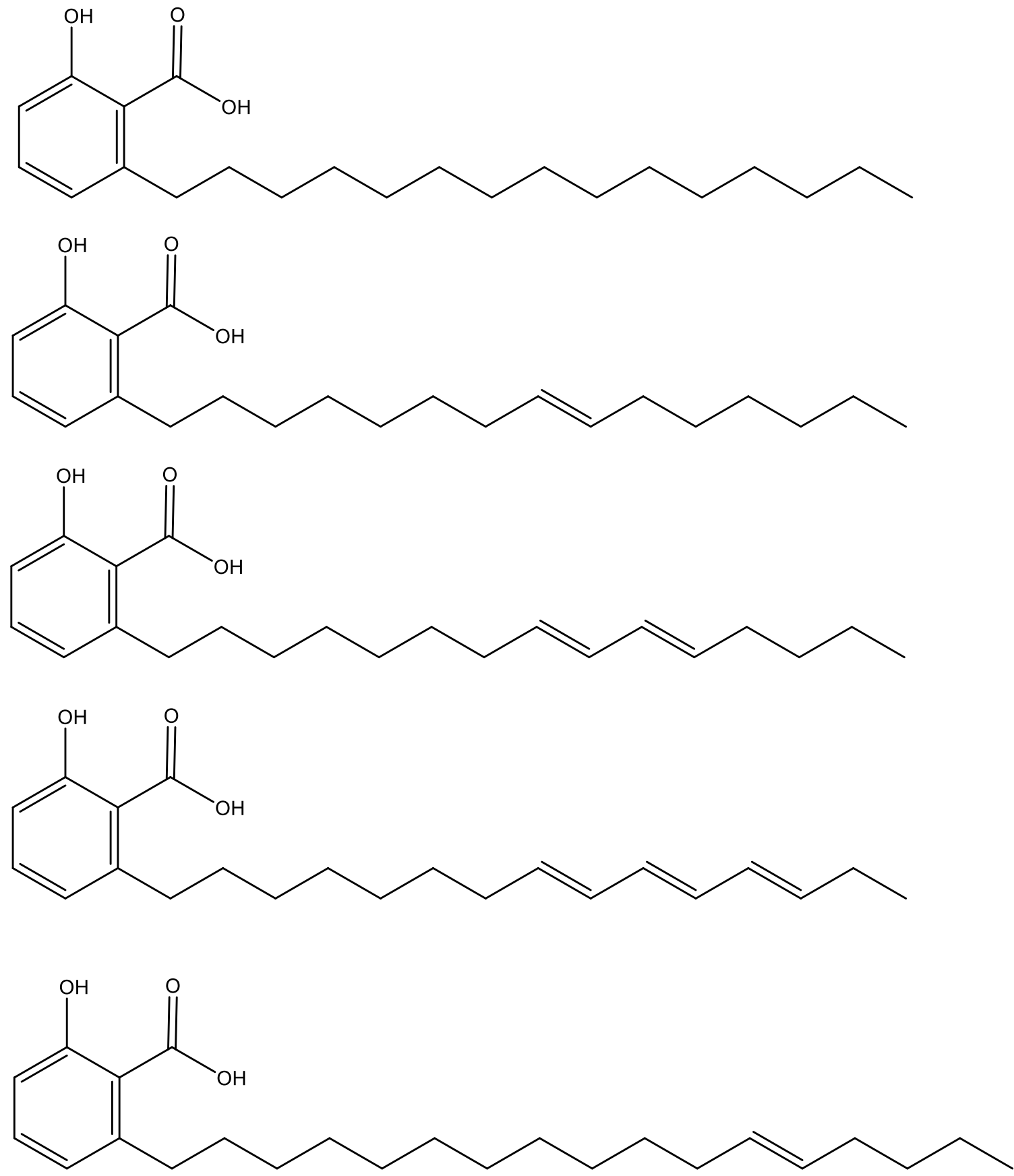

Figure 1: Structures of various AnAcs. From the top to the bottom: $22: 0 ; 22: 1{ }^{\omega 7}$; $22: 2^{\omega 5,7} ; 22: 3^{\omega 3,5,7} ; 24: 1^{\omega 5}$. 


\section{Presence in Biological Tissues}

Anacardic acids are commonly found in cashew nuts (Anacardium occidentale), the nuts and leaves of ginkgo trees (Ginkgo biloba), and other plants, such as mango (Mangifer indica) or pistachio (Pistacia vera) (Gellerman \& Schlenk, 1968). Furthermore, high levels (81\%) of unsaturated $22: 1^{\omega 5}$ and $24: 1^{\omega 5}$ provide a means of defense against pests (e.g., spider mites and aphids) for Pelargonium $\times$ hortorum (geranium) (David J Schultz et al., 1996). Both production from fatty acid precursors and secretion of AnAcs in geranium plants, occur in tall glandular trichomes located on the leaves and pedicles of the plant.

Potential Use as Therapeutic Agents

Much research has been carried out to uncover the benefits of AnAcs on human health. As of 2011, 20 different pharmacological roles had been reported for both saturated and unsaturated forms of AnAcs (Mahadevappa Hemshekhar, Martin Sebastin Santhosh, Kempaiah Kemparaju, \& Girish, 2011). For example, Castillo-Juárez et al. demonstrated that AnAcs isolated from Amphipterygium adstringens (cuachalalate), a plant used in traditional Mexican medicine, have antibacterial activity against Helicobacter pylori (H. pylori) and when coupled with proton-pump inhibitors, they could be used as a potential therapeutic treatment (Castillo-Juarez, Rivero-Cruz, Celis, \& Romero, 2007). Helicobacter pylori is now widely accepted as the cause of the most common form of gastric ulceration and is considered to be the leading cause of gastric cancer worldwide (Correa \& Houghton, 2007; Dixon, 2001). Infection of $H$. pylori leads to a lifetime immune 
response from the host which eventually leads to mucosal atrophy, metaplasia, and dysplasia toward gastric cancer (Correa \& Houghton, 2007).

Furthermore, AnAcs play a more direct role in cancer inhibition by directly affecting cell proliferation and apoptosis. Schultz et al. studied the effects of purified $24: 1^{\omega 5}$ on the proliferation of estrogen-dependent and estrogenindependent/antiestrogen-resistant breast cancer cells (D. J. Schultz et al., 2010). Interestingly, $24: 1^{{ }^{5}} \mathrm{AnAc}$ inhibited breast cancer cell proliferation by interacting with the Estrogen Receptor $\alpha(E R \alpha)$ DNA Binding Domain (DBD) thus preventing protein/DNA interaction leading to an increase in cell proliferation. More importantly, 24:1 ${ }^{\omega 5} \mathrm{AnAc}$ inhibits breast cancer cell proliferation in both endocrine-sensitive and endocrine-insensitive cells thus suggesting AnAcs as potentially beneficial breast cancer therapies. Table 1 below presents a more complete list of AnAcs uses for different therapies (Mahadevappa Hemshekhar et al., 2011).

\section{Analysis of Anacardic Acids}

In 1983, AnAcs were collected in the trichome exudate from geranium plants by touching a leaf to a glass microscope slide which was then rinsed with ethyl acetate and purified for further analysis via various chromatographic techniques and spectroscopic techniques (Gerhold, Craig, \& Mumma, 1984). Anacardic acid isolation and purification is most commonly achieved as described in reference 13 (D. J. Schultz, Olsen, Cobbs, Stolowich, \& Parrott, 2006) with or without slight modifications. Briefly, pedicels are isolated from 
Table 1: Various pharmacological roles for different AnAcs (Mahadevappa Hemshekhar et al., 2011)

\begin{tabular}{|c|c|c|c|}
\hline \multirow[b]{2}{*}{ Compounds } & \multicolumn{3}{|l|}{ Pharmacological } \\
\hline & Role & Model used to test & Dose \\
\hline \multirow{22}{*}{ Anacardic Acid (C22:0) } & ROS generation & & \\
\hline & inhibition & & $0.053 \pm 0.005 \mathrm{mM}$ \\
\hline & Xanthine oxidase & & \\
\hline & inhibition & & $0.0043 \pm 0.0005 \mathrm{mM}$ \\
\hline & & Propionibacterium & \\
\hline & Anti-bacterial & acnes & $0.0015 \mathrm{mg} / \mathrm{mL}$ \\
\hline & & Corynebacterium & \\
\hline & & xerosis & $0.0062 \mathrm{mg} / \mathrm{mL}$ \\
\hline & & S. aureus & $0.025 \mathrm{mg} / \mathrm{mL}$ \\
\hline & & MSSA ATCC12598 & $0.0031-0.0062 \mathrm{mg} / \mathrm{mL}$ \\
\hline & & MRSA & \\
\hline & & B. subtilis & \\
\hline & $\begin{array}{l}\text { Zoosporicidal } \\
\text { activity }\end{array}$ & $\begin{array}{l}\text { Aphanomyces } \\
\text { cochlioides }\end{array}$ & \\
\hline & $\begin{array}{l}\text { Anti-parasitic } \\
\text { activity }\end{array}$ & $\begin{array}{l}\text { Colorado potato } \\
\text { beetle larvae }\end{array}$ & \\
\hline & HATs inhibition & & $0.0085 \mathrm{mM}$ \\
\hline & p300 & & \\
\hline & PCAF & & $0.005 \mathrm{mM}$ \\
\hline & Cytotoxicity & & $0.008 \mathrm{mM}$ \\
\hline & PfGCN5 HATs & & \\
\hline & inhibition & & \\
\hline & NFKB inhibition & & \\
\hline & $\begin{array}{l}\text { Anti-cancer } \\
\text { activity }\end{array}$ & $\begin{array}{l}\text { Pituitary adenoma } \\
\text { cells, melanoma cells }\end{array}$ & \\
\hline
\end{tabular}




\begin{tabular}{|c|c|c|c|}
\hline & $\begin{array}{l}\text { Aurora kinase A } \\
\text { activation }\end{array}$ & & \\
\hline & Anti-obase activity & Wistar rats & \\
\hline & $\begin{array}{l}\text { Tyrosinase } \\
\text { inhibition }\end{array}$ & Mashroom tyrosinase & $0.18 \mathrm{mg} / \mathrm{mL}$ \\
\hline & Urease inhibition & & $0.12 \mathrm{mg} / \mathrm{mL}$ \\
\hline & $\begin{array}{l}\text { Selective metal ion } \\
\text { chelation }\end{array}$ & & \\
\hline Anacardic Acid (C22:1) & LOX-15 inhibition & Soybean lipoxygenase & $0.05 \mathrm{mM}$ \\
\hline & Cytotoxicity & HeLa cells & $0.01 \mathrm{mM}$ \\
\hline Anacardic Acid (C22:2) & Anti-bacterial & Helicobacter pylori & $0.2 \mathrm{mg} / \mathrm{mL}$ \\
\hline Anacardic Acid (C22:3) & $\begin{array}{l}\text { Anti-bacterial, } \\
\text { Molluscidal activity }\end{array}$ & H. pylori, Snails & $0.2 \mathrm{mg} / \mathrm{mL}$ \\
\hline Anacardic Acid (C24:1) & $\begin{array}{l}\text { Anti-proliferation } \\
\text { of } E R \alpha\end{array}$ & $\begin{array}{l}\text { MCF-10A, MCF-7, } \\
\text { MDA-MB-231 breast } \\
\text { cancer cells }\end{array}$ & \\
\hline
\end{tabular}


geranium plants and washed with chloroform. After washing, AnAcs are isolated from the crude extract via separation using a silica gel $\mathrm{G}$ column. Fractions containing crude extract were pooled and $22: 1^{\omega 5}$ and $24: 1^{\omega 5}$ were furthered separated using high pressure liquid chromatography (HPLC).

The paragraphs below summarize the principles and instrumentation of fluorescence spectroscopy and mass spectroscopy, as well as previous applications of these methods to the analysis of AnAcs.

\section{Molecular Fluorescence (FL) Spectroscopy}

1a) Physical Principles and Basic Instrumentation

A molecular fluorophore is a species that absorbs energy over a specific wavelength range and then, after vibrational relaxation takes place, energy is emitted at longer wavelengths. Fluorescence lifetimes range from nano- to microseconds (Sauer, Hofkens, \& Enderlein, 2010). When dealing with fluorescence, the lowest energy transitions $\left(n \rightarrow \pi^{*}\right.$ or $\left.\pi \rightarrow \pi^{*}\right)$ are of importance. Wavelengths between 200-600 nm cause $n \rightarrow \pi^{*}$ and $\pi \rightarrow \pi^{*}$ transitions with the $n \rightarrow \pi^{*}$ requiring longer wavelengths (Ingle Jr \& Crouch, 1988).

The process of absorption and emission of light is illustrated using a Jablonski Energy level diagram as shown in the Figure 2 below. Two of the most important parameters in fluorescence are fluorescence lifetime and quantum yield. Fluorescence lifetime $(\tau)$ is the mean duration time a fluorophore remains in the excited state or the time required for about $63 \%$ of an initial number of excited molecules to return to the ground state 


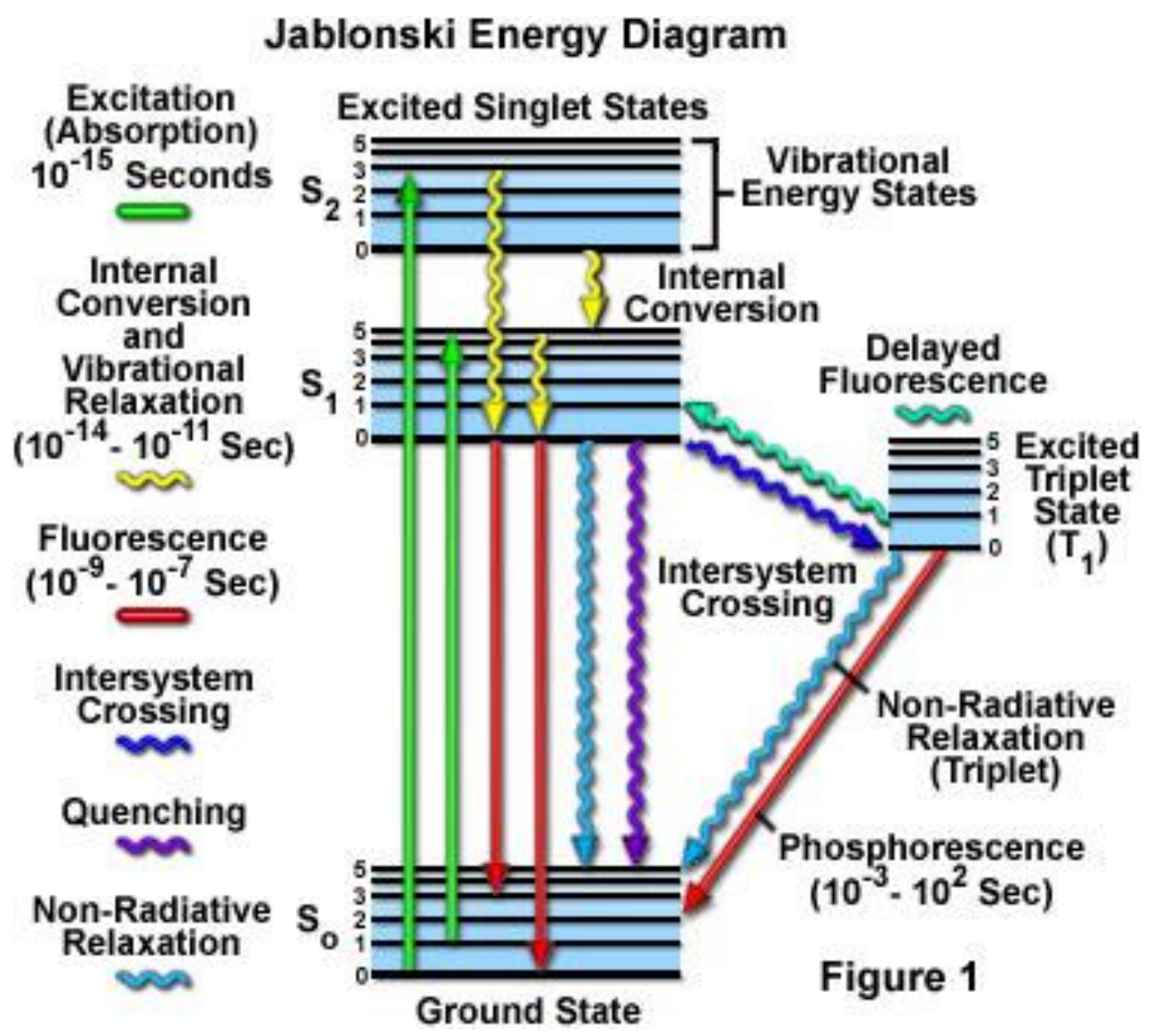

Figure 2: Jablonski energy-level diagram depicting various processes possible after absorption of light by a typical organic fluorophore ("Olympus Microscopy Resource Center | Jablonski Energy Diagram - Java Tutorial," 2015). 
(Sharma \& Schulman, 1999; X. F. Wang \& Herman, 1996) (See Figure 3

below). The intensity decay of a fluorophore that has been excited is given by the equation:

$$
I(t)=I_{0} e^{-\left(\frac{t}{\tau}\right)}
$$

Where $I_{0}$ is the intensity at $\mathrm{t}=0$ and $\tau$ is the fluorescence lifetime. The decay time can be influenced by the rates of radiative and nonradiative processes $\left(k_{r}\right.$ and $\left.k_{n r}\right)$, as well as, collisional quenching $\left(k_{q}[Q]\right)$. Therefore, the measured fluorescence lifetime $\tau$, is given by:

$$
\tau=\frac{1}{k_{r}+k_{n r}+k_{q}[Q]}
$$

Quantum yield $\left(\phi_{f}\right)$ is the ratio of the number of photons emitted to the number of photons absorbed (Lakowicz, 2007). Quantum yield can also be described in terms of rates as seen in the equation below:

$$
\phi_{f}=\frac{k_{f}}{k_{f}+\sum k_{d}}
$$

where $k_{f}$ is the rate constant for fluorescence and $\sum k_{d}$ is the sum of the rate constants for deactivation via nonradiative processes like dynamic quenching, intersystem crossing, internal conversion, etc. (Sharma \& Schulman, 1999). Lastly, photochemical lifetime is limited by photobleaching. 


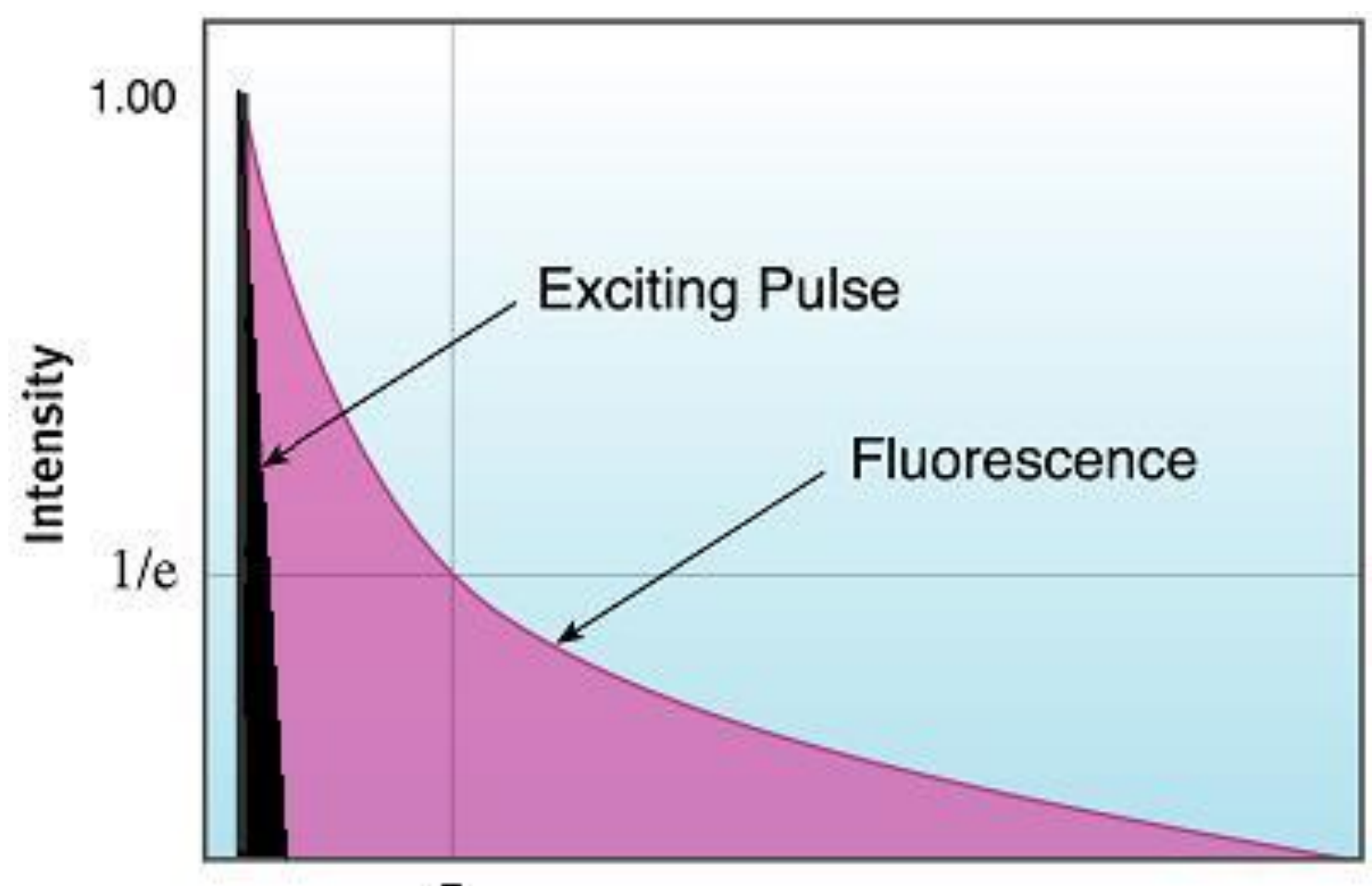

$\tau$

\section{Time}

Figure 3: Exponential decay of fluorescence intensity after a molecule has undergone excitation. The FL lifetime (T) is the time required for about $63 \%$ of the initial number of excited molecules to return to the ground state ("ISS | Technical Notes | Fluorescence Lifetime," 2015). 
1b) Previous Studies of Anacardic Acids by FL

Since rigid molecules with conjugated pi systems typically make good fluorophores, the benzoic portion of AnAcs made them good candidates for fluorescence studies. To date, there are no reports on the fluorescence properties of AnAc. However, Gerhold et al. (1984) determined that the maximum wavelengths of absorption for ultraviolet-visible spectroscopy (UV-Vis) were $208 \mathrm{~nm}$ and $302 \mathrm{~nm}$ for AnAcs dissolved in ethanol (Gerhold et al., 1984).

\section{1c) Tissue Imaging by FL Spectroscopy: Advantages and Disadvantages}

Today, fluorescence plays a vital role in biotechnology and science. Fluorescent probes have been preoperatively administered to patients for fluorescence imaging of hepatocellular carcinoma (Kokudo \& Ishizawa, 2012). The difficulties with in vivo fluorescence imaging are: absorption and scattering of light by tissue making signal collection difficult, the fluorescence probe must be biologically stable, and the fluorescence probe must accumulate in the intended imaging location (Rao, Dragulescu-Andrasi, \& Yao, 2007). In order to overcome some of these difficulties, much research has been focused on developing better fluorescent probes (Hintersteiner et al., 2005; Montet, Rajopadhye, \& Weissleder, 2006; So, Xu, Loening, Gambhir, \& Rao, 2006). In 2008, Chalfie et al. (1994) were awarded the Nobel Prize in chemistry for the use green fluorescent protein (GFP) isolated from jellyfish as a marker for gene expression by cloning the gene sequence into Caenorhabditis elegan (nematodes)(Chalfie, Tu, Euskirchen, Ward, \& Prasher, 1994). Currently, there are no reported studies on the fluorescence of AnAcs. 


\section{Mass Spectrometry (MS)}

In 1983, Gerhold et al. used a gas-liquid chromatography mass spectrometer to help determine the identity of unknown compounds in the exudate (AnAcs) secreted by geraniums (Gerhold et al., 1984).

More recently, electrospray ionization (ESI), in the negative mode, was used successfully for the identification of purified AnAcs, as well as for the identification of these compounds in the liquid extract of cashew nut shells. Because $\mathrm{ESI}$ is a relatively soft form of ionization, fragmentation is minimal thus enabling the detection of parent ions. Cesla et al. successfully conducted tandem mass spectrometry (MS/MS) to further study AnAcs by observing that fragmentation patterns in alkyl chains were dependent upon the degree of unsaturation. However, the location of the double bond could not be determined (Cesla, Blomberg, Hamberg, \& Jandera, 2006).

\section{2a) Physical Principles and Basic Instrumentation}

One main component of all mass spectrometers is the ion source that produces ions via gas phase ionization. The ionization process can be classified as either soft or hard. Hard ionization is a high energy ionization process which causes extensive fragmentation of the parent molecule. Fragmentation of the parent ion is a disadvantage of hard ionization when dealing with a mixture. However, if a separation step is added, such as GC or HPLC, hard ionization techniques such as electron impact (EI) enable the structural identification of the analyte from the fragmentation pattern. 
In contrast to hard ionization, a soft ionization is a lower energy process that does not cause extensive fragmentation of the parent molecule and thus typically produces a less complex mass spectrum. The rest of this chapter will focus on MALDI. A more complete list of hard and soft ionization process can be seen in Table 2.

2b) Ionization Approaches

ESI

As mentioned previously, ESI allows for the observation of parent ions due to the softness of the ionization. One main disadvantage of ESI, as compared to MALDI, stems from the ionization process of ESI. In ESI, the analyte is dissolved in a suitable solvent which is then passed through a very thin capillary held at high voltage that allows for electrical charge transfer. If salts are present in the sample, they can clog the capillary tube and compete with the analyte for charge. However, ESI does not require the use of a matrix which is one main disadvantage to using an ionization process like MALDI.

MALDI is a soft ionization process that uses a laser (typically, a $\mathrm{N}_{2}$ laser that emits at $337 \mathrm{~nm}$ ) as a means for ionization. One main advantage to the use of MALDI is the ability for in situ analysis. Lastly, MALDI essentially produces singly charged species, in the absence of ions with multiple charges, thus reducing the complexity of the spectrum unlike in ESI where multiply charged species are produced (Karas, Gluckmann, \& Schafer, 2000). 
Table 2: Table depicting common soft and hard ionization methods for mass spectrometry analysis.

\begin{tabular}{|ll|}
\hline Soft Ionization & Hard lonization \\
\hline Matrix Assisted Laser Desorption Ionization (MALDI) & $\begin{array}{l}\text { Electron Impact } \\
\text { (EI) }\end{array}$ \\
\hline Electrospray Ionization (ESI) & \\
\hline Fast Atom Bombardment (FAB) & \\
\hline Chemical Ionization (CI) &
\end{tabular}




\section{Matrix Assisted Laser Desorption Ionization (MALDI)}

In 1985, Karas et al. were studying a mixture of alanine and tryptophan using laser desorption ionization and noticed that the best mass spectrum was obtained when the laser irradiance was equal to the threshold irradiance for tryptophan (Karas, Bachmann, \& Hillenkamp, 1985). Since the mass spectrum signal from alanine was strong despite the laser irradiance being a tenth of that necessary to obtain a strong signal from alanine alone, the researchers concluded that tryptophan acted as an absorbing matrix leading to ion formation of both amino acids and thus the term "matrix-assisted" was introduced ((Karas et al., 1985). In 1987, Karas and Hillenkamp published the first paper demonstrating the ability of matrix-ultraviolet laser desorption ionization to detect compounds with masses greater than 10,000 daltons (Karas \& Hillenkamp, 1988). Since then, researchers have been using MALDI-MS to detect compounds with varying molecular weights, from low molecular weights such as lipids to large proteins.

As suggested by the name, MALDI employs a matrix that absorbs at the laser wavelength. The excited matrix transfers some of the excess energy to the analyte(s) which are then desorbed and ionized. The most basic workflow of any MALDI experiment can be described as: deposition of matrix and sample onto a suitable surface such as stainless steel or glass, irradiation of sample with laser, and desorption/ionization of sample.

The most common approach of matrix-sample deposition is the drieddroplet method. This method requires that sample and matrix be dissolved in a 
suitable solvent individually. Next, the sample and matrix are mixed (molar ratios between $1: 2500$ to $1: 10,000)$ and then deposited onto the surface of a plate that is typically made of stainless steel. Deposition can also be carried out in a stepwise fashion by first spotting the matrix onto the surface, allowing it to dry, and then spotting the sample onto of the dried matrix spot. This method is called the thin layer (or sandwich) method. However, MALDI matrix-sample preparation/deposition is often influenced by what produces the most homogenous analyte-matrix co-crystallization and gives the best signal to noise ratio. Lastly, since MALDI allows for in situ imaging, new matrix deposition methods have been reported. Schwartz et al. used a deactivated glass spray nebulizer to spray the matrix directly onto the tissue surface to increase matrix homogeneity and matrix co-crystallization with the analyte (Schwartz, Reyzer, \& Caprioli, 2003). Similarly, Baluya et al. used an Epson R320 photo printer as a means of matrix deposition (Baluya, Garrett, \& Yost, 2007). Lastly, in 2006, Aerni et al. used an acoustic reagent multispotter to eject matrix droplets onto the surface of mouse brain tissue; the group reported improved mass spectral quality and reproducibility when compared to manual spotting (Aerni, Cornett, \& Caprioli, 2006).

The matrix choice is critical for the success of any MALDI experiment. Although there is no limitation on the type of substance (organic, inorganic, etc.), there are several basic properties that should be considered when choosing the matrix. First, the matrix compound should have a strong absorbance that corresponds to the wavelength of the laser. Second, the matrix should be stable 
under vacuum since this is where desorption/ionization take place (Krause, Stoeckli, \& Schlunegger, 1996).

Since the advent of MALDI, much work has been done to better understand the desorption and ionization processes. As stated above, the role of the matrix is to absorb the laser energy and transfer it to the analyte. This process is governed by Beer's law:

$$
H=H_{0}^{*} e^{-\alpha z}
$$

where $\mathrm{H}$ is the laser fluence at depth $\mathrm{z}$ in the sample, $\mathrm{H}_{0}$ is the laser fluence at the surface of the sample, and $\alpha$ is the absorption coefficient which is governed by the product of wavelength-dependent molar absorption coefficient $\alpha_{0}$ (a matrix property) and the concentration of absorbing molecules (Hillenkamp, Jaskolla, \& Karas, 2014). Furthermore, the energy density, or energy absorbed per unit volume, $\mathrm{E}_{\mathrm{a}} / \mathrm{V}$, can be described as:

$$
E_{a} / V=\alpha^{*} H
$$

Interpretation of this expression suggest that if a matrix with a high absorption coefficient is selected, sufficient energy density leading to desorption and ionization can be achieved at relatively low $\mathrm{H}_{0}$ (Hillenkamp et al., 2014). See Figure 4 below for a depiction of the desorption process.

A long standing theory for the generation of ions during the ablation/desorption process is the multi-photon ionization theory. The simplest case would be a sequential two-photon ionization process in which one photon 


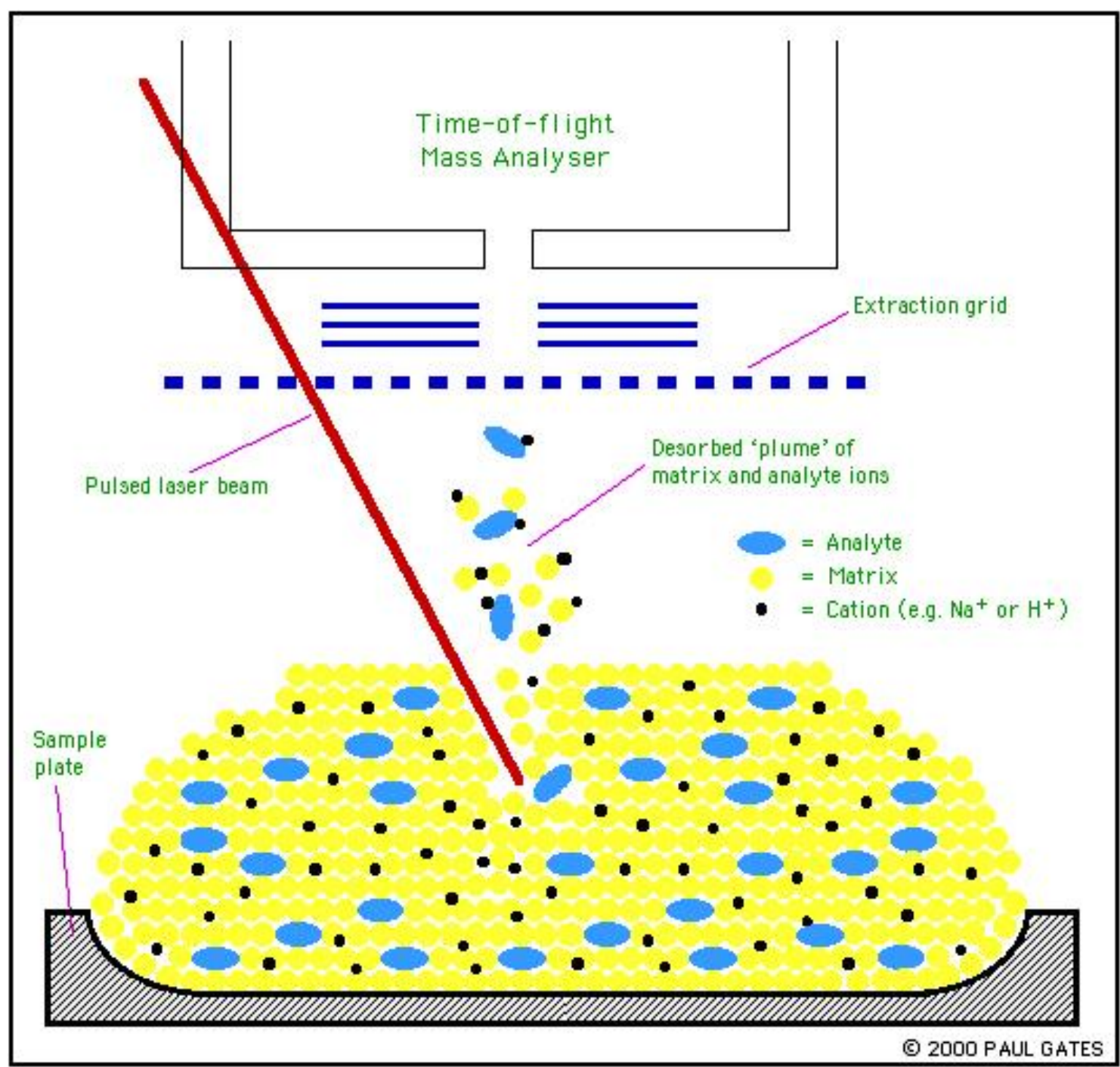

Figure 4: Pictorial description of the desorption/ionization process in MALDI (Bell). 
from the laser directly excites a matrix molecule to an energy level below the ionization threshold and while in the short lived excited state, another photon excites the matrix molecule resulting in an excited state that is still below the ionization threshold. This process results in a total of two photons for excitation and the generation of a matrix cation radical and free electron.

$$
M \stackrel{h v}{\rightarrow} M^{*} \stackrel{h v}{\rightarrow} M^{+\cdot}+e^{-}
$$

However, the fluence of a typical $337 \mathrm{~nm} \mathrm{~N} \mathrm{~N}_{2}$ laser is not sufficient to overcome the ionization potential of common matrices such as 2,5 dihydroxybenzoic acid (DHB). Thus, it was suggested that the extra energy needed could be thermal and provided by the rather hot plume, but this explanation would only work for situations where the two-photon ionization process provided sufficient energy to nearly reach the ionization potential of the matrix which is not true regarding most commonly used matrices (Allwood, Dyer, Dreyfus, \& Perera, 1997; Zenobi \& Knochenmuss, 1998).

The most accepted explanation of the generation of ions in MALDI is the excited-state proton transfer theory. This theory suggests that while a matrix molecule is in its excited state, it becomes more acidic making it easier for a neighboring analyte or ground-state matrix molecules to accept the proton before the excited matrix molecule relaxes back to the ground state. One aspect about this theory that makes it rather attractive is the fact that it would only require one photon (Zenobi \& Knochenmuss, 1998). 


$$
\begin{gathered}
M \stackrel{h v}{\rightarrow} M^{*} \\
M^{*}+A \rightarrow(M-H)^{-}+A H^{+} \\
M^{*}+M \rightarrow(M-H)^{-}+M H^{+}
\end{gathered}
$$

Although these are only two of the fairly common theories attempting to describe the MALDI ionization process, many more exist; each with its own pros and cons.

\section{2c) Mass Analyzers}

There are several different types of mass analyzers that are currently in use. One, which will be discussed in the next section, is the time-of-flight (TOF) which offers high mass accuracy and resolving power. However, the most common mass analyzer is the quadrupole mass filter. The quadruple is made up of four parallel rods connected to a direct current (DC) and radiofrequency (rf) voltage supply. As ions accelerate through the quadrupole, the rod potentials alternate polarity thus causing the ions to move back and forth between the rods. Depending on the DC and rf voltages, an ion will either collide with one of the poles or succeed in passing through the quadrupole thus allowing it to be detected (Montaudo \& Lattimer, 2010). The disadvantages of the quadrupole are the poor mass accuracy and also resolving power. See the Table 3 below for a complete list of mass analyzers.

Time-of-Flight (TOF)

The time-of-flight mass analyzer relies on the concept that ions with the same kinetic energy but different masses will travel at velocities inversely 
Table 3: Comparison of common mass analyzers. From Lambert .....(Complete this reference)

TABLE 13-17

Characteristics of Mass Analyzers

\begin{tabular}{|c|c|c|c|c|c|c|c|}
\hline Method & $\begin{array}{l}\text { Quantity } \\
\text { Measured }\end{array}$ & $\begin{array}{c}\text { Mass } \\
\text { Analysis } \\
\text { Equation }\end{array}$ & $\begin{array}{c}\text { Mass-to- } \\
\text { Charge } \\
\text { Range* }\end{array}$ & $\begin{array}{c}\text { Reso- } \\
\text { lution*t }\end{array}$ & $\begin{array}{c}\text { Mass } \\
\text { Measure- } \\
\text { ment } \\
\text { Accuracy* }\end{array}$ & $\begin{array}{c}\text { Dynamic } \\
\text { Range }^{\ddagger}\end{array}$ & $\begin{array}{c}\text { Oper- } \\
\text { ating } \\
\text { Pressure } \\
\text { (torr) }\end{array}$ \\
\hline $\begin{array}{l}\text { Sector } \\
\text { magnet }\end{array}$ & $\begin{array}{l}\text { Momentum/ } \\
\text { charge }\end{array}$ & $14-24$ & $10^{4}$ & $10^{5}$ & $<5 \mathrm{ppm}$ & $10^{7}$ & $10^{-6}$ \\
\hline $\begin{array}{l}\text { Time of } \\
\text { flight }\end{array}$ & Flight time & $14-27$ & $10^{6}$ & $10^{3}-10^{4}$ & $0.1-0.01 \%$ & $10^{4}$ & $10^{-6}$ \\
\hline $\begin{array}{l}\text { Quadrupole } \\
\text { ion trap }\end{array}$ & Frequency & $14-32$ & $10^{4}-10^{5}$ & $10^{3}-10^{4}$ & $0.1 \%$ & $10^{4}$ & $10^{-3}$ \\
\hline $\begin{array}{l}\text { Quadrupole } \\
\text { Cyclotron } \\
\text { resonance }\end{array}$ & $\begin{array}{l}\text { Filters for } m / z \\
\text { Frequency }\end{array}$ & $\begin{array}{l}14-29 \\
14-35\end{array}$ & $\begin{array}{c}10^{3}-10^{4} \\
10^{5}\end{array}$ & $\begin{array}{l}10^{3} \\
10^{6}\end{array}$ & $\begin{array}{c}0.1 \% \\
<10 \mathrm{ppm}\end{array}$ & $\begin{array}{l}10^{5} \\
10^{4}\end{array}$ & $\begin{array}{l}10^{-5} \\
10^{-9}\end{array}$ \\
\hline
\end{tabular}

* At $1000 \mathrm{Da} /$ charge.

$\uparrow$ Mass/peak width.

₹ Number of orders of magnitude of concentration over which response varies linearly. 
proportional to their masses (Smith \& Busch, 1999). Assuming that their kinetic energies are equal and they enter the drift region at the same time then (Barker, Ando, \& Davis, 1999):

$$
\begin{aligned}
& \frac{m_{1} v_{1}^{2}}{2}=\frac{m_{2} v_{2}^{2}}{2} \quad \text { Eq. } 3 \\
& \frac{m_{1}}{m_{2}}=\left(\frac{v_{2}}{v_{1}}\right)^{2} \quad \text { Eq. } 4
\end{aligned}
$$

for singly charges ions with mass $m_{1}$ and $m_{2}$ with velocities $v_{1}$ and $v_{2}$.

Furthermore, the time, $t$, it takes for an ion to travel a distance, $d$, is given by the equation

$$
t=\frac{d}{v} \text { Eq. } 5
$$

Realizing that the distance, $d$, traveled for each ion is the same, then setting distance equal and substituting equation (4) gives

$$
\begin{gathered}
t_{1} v_{1}=t_{2} v_{2} \text { Eq. } 6 \\
\frac{t_{1}}{t_{2}}=\frac{v_{2}}{v_{1}}=\sqrt{\frac{m_{1}}{m_{2}}} \text { Eq. } 7
\end{gathered}
$$

The above equation holds true for singly charged ions. However, the transit time (time for ion to reach detector) for ions not singly charged, requires that the charge be considered. The velocity of an ion with charge, $z$, accelerated with a voltage, $V$, can be expressed as (Barker et al., 1999): 


$$
v=\sqrt{\frac{2 z V}{m}} \text { Eq. } 8
$$

Substituting equation (8) into equation (5) shows how charge factors into the time, $t$, needed for an ion to travel a distance, $d$.

$$
t=d \sqrt{\frac{m}{2 z V}} \text { Eq. } 9
$$

One major problem with the time-of-flight mass analyzer is that not all ions of the same species have the same initial kinetic energy. Therefore, they do not reach the detector at the same time. To overcome differences in initial kinetic energy between ions of the same $\mathrm{m} / \mathrm{z}$, time-of-flight mass analyzers are often equipped with a reflectron (Mamyrin, Karataev, Shmikk, \& Zagulin, 1973). The reflectron is an electrostatic lens at the end of the flight region that contains a voltage gradient. Ions with higher kinetic energies penetrate deeper into the voltage field thus extending the flight distance and time so that ions of the same $\mathrm{m} / \mathrm{z}$ with different kinetic energies are reflected back and arrive at the detector at the same time (Figure 5).

2d) Previous Studies of Anacardic Acids by MS

To date, not much work has been dedicated to studying AnAcs using MS exclusively. Gerhold et al. were the first to apply MS to identify AnAcs (Gerhold et al., 1984). Furthermore, Cesla et al. used mass spectrometry in conjunction with micellar electrokinetic chromatography as a means of characterizing AnAcs. (Cesla et al., 2006). To the best of our knowledge, this work represents the first 


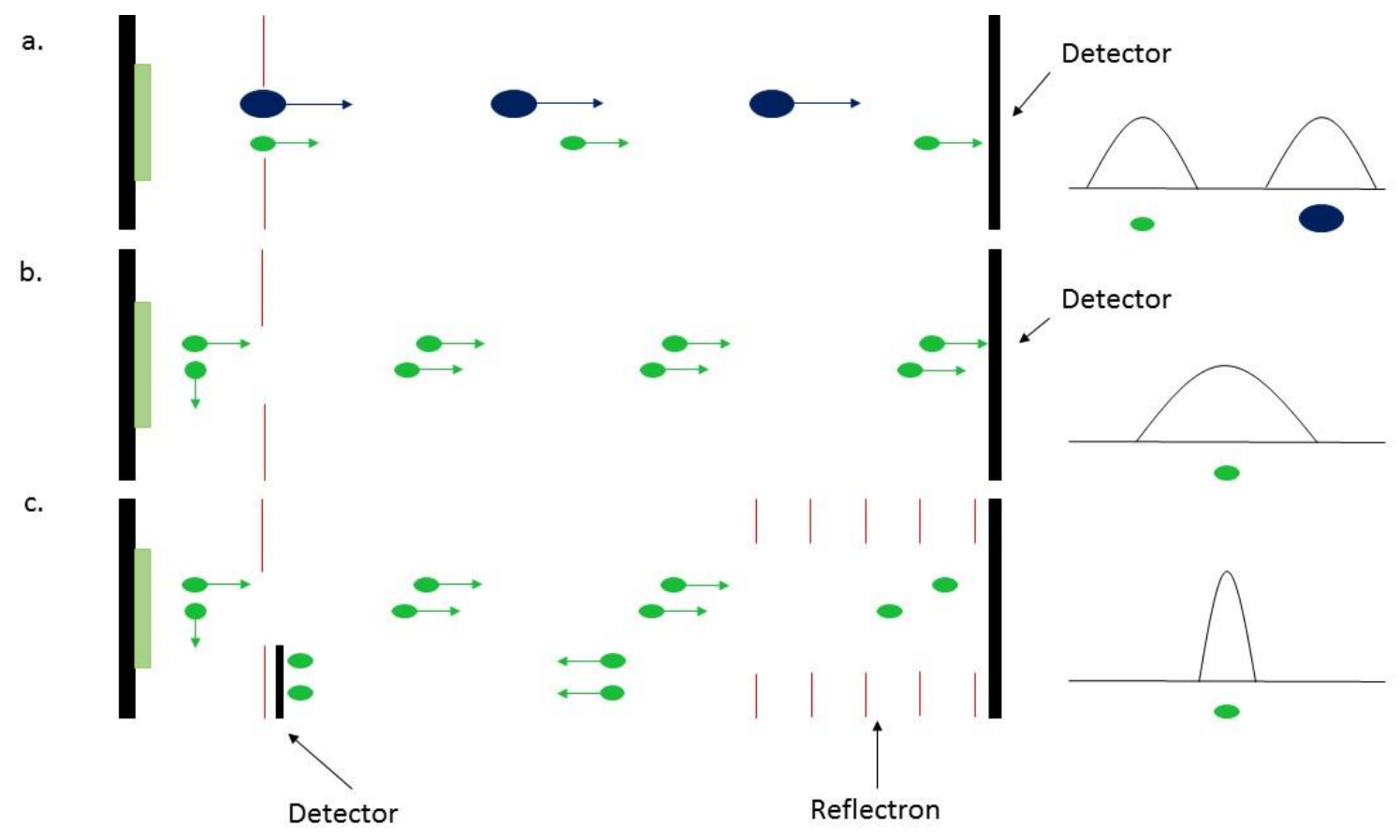

Figure 5: (a) Time-of-flight (TOF) mass spectral (MS) analysis, in the linear mode, of two ions with different $\mathrm{m} / \mathrm{z}$ values. (b) TOF-MS analysis, in the linear mode, of two ions with the same $\mathrm{m} / \mathrm{z}$ but different kinetic energies. (c) same analysis as the middle image but with the addition of the reflectron. Notice the improvement in mass resolution between (b) and (c). 
example of using MALDI-MS exclusively to study AnAc in situ. Lastly, this thesis presents the first example of using MALDI-MS as a means of imaging AnAcs in an effort to differentiate between geranium species and for future studies involving gene silencing.

2e) Mass Spectrometry Imaging (MSI): Advantages/Disadvantages and Challenges

Being able to observe the spatial distribution of molecules within cells and tissue plays an important role in the understanding of biological process. In 1997, Caprioli et al. were first in reporting the use of MALDI-MS to generate ion images of biological samples (Caprioli, Farmer, \& Gile, 1997). Since then, much work has been done using MALDI-MS for imaging with improved resolution, to improve our ability to understand disease states, examine drug distribution, etc. As stated previously, MALDI-MS allows for in situ analysis thus making mass spectrometry imaging (MSI) using MALDI-MS a very promising technique and thus will be the focus of the rest of this thesis.

One of the most important factors in MSI is the ability to preserve the spatial distribution of the analytes. Complex sample preparation techniques can compromise the integrity of analyte distribution thus making it harder to acquire accurate images of the sample (Amstalden van Hove, Smith, \& Heeren, 2010). Although sample preparation is dependent upon the nature of the sample, MALDI-MSI always requires the use of a matrix. With the advent of specialized devises for matrix application, it has become easier to apply a homogenous layer of matrix onto samples which helps to improve spatial resolution. During the 
application of the matrix, it is important that the matrix co-crystallize with the analyte without displacing it from its original location; to help with this, some groups developed solvent-free matrix application techniques (Hankin, Barkley, \& Murphy, 2007; Trimpin, Inutan, Herath, \& McEwen, 2010). Also, the smaller the matrix crystals, the greater the spatial resolution (Trimpin et al., 2010).

Once the sample is placed on the MALDI plate and loaded into the instrument, the image is acquired by scanning the laser over the sample surface. If the matrix crystal size is smaller than the diameter or the laser, $50-150 \mu \mathrm{m}$, then the image resolution is generally governed by laser diameter (Schwartz et al., 2003). Each laser irradiation location corresponds to a pixel in the image. The time needed for image acquisition is determined by spatial resolution requirements, laser repetition rate, spot-to-spot sample repositioning time, and data analysis (Hsieh, Chen, \& Korfmacher, 2007). After a spectrum is obtained for each laser location, the data is processed and an image is made based on the available $\mathrm{m} / \mathrm{z}$ signals. Today, programs such as BioMap or MALDIVision exist making it easier to convert spectral data into image data. See Figure 6 below for the MALDI-TOF-MSI workflow.

\section{Reasons for this project}

The main goal of this thesis was to generate ion images of AnAcs using MALDI-MS. To date, no such work has been demonstrated. Ion images of AnAcs would be beneficial in detecting gene silencing effects, in geranium plants, using RNAi. Specifically, MS ion images are beneficial to studying gene silencing effects because of the ability to discern the spatial distribution of AnAcs. 


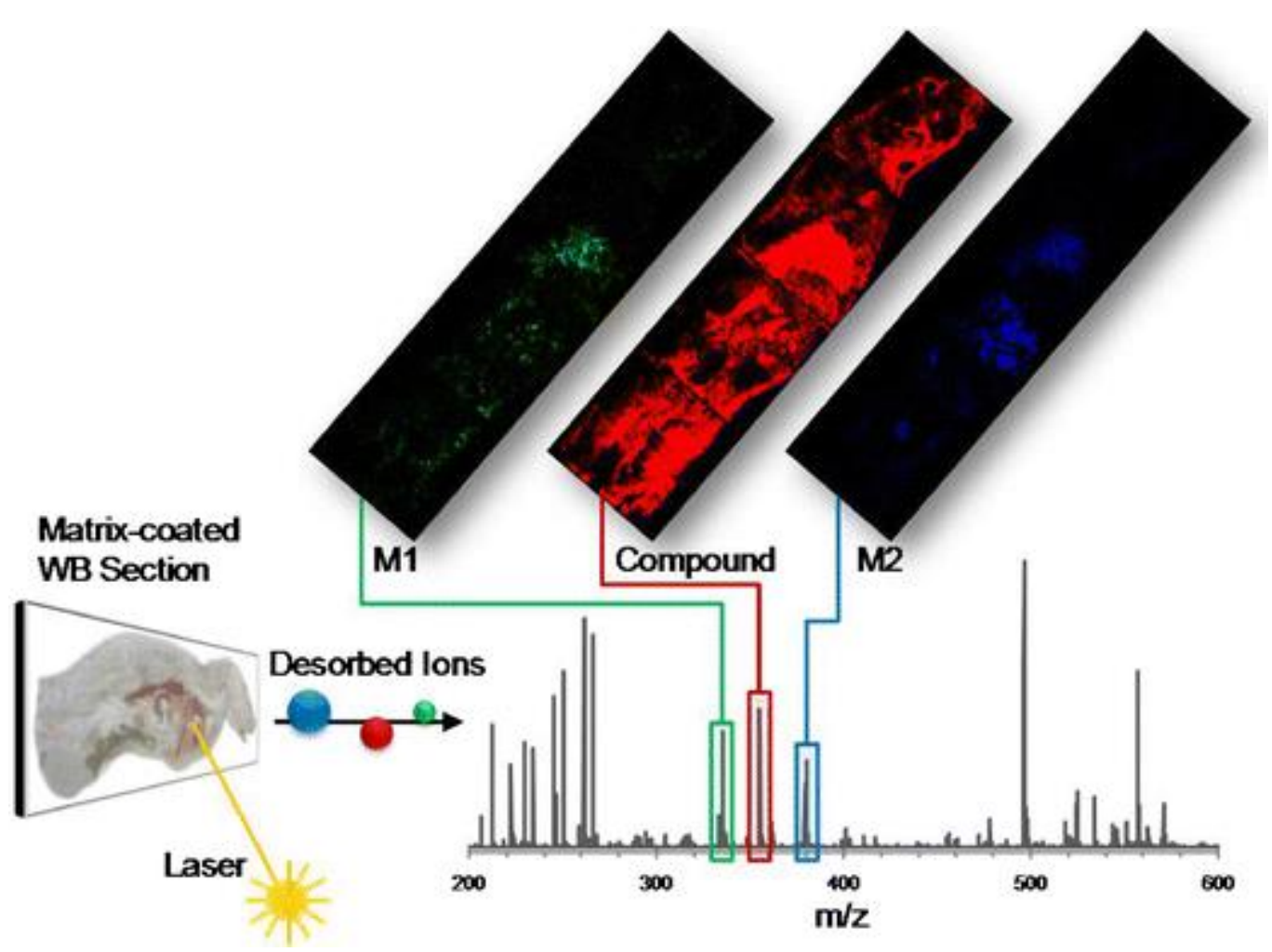

Figure 6: Workflow depicting the generation of MALDI-MS ion images (Solon, Schweitzer, Stoeckli, \& Prideaux, 2010). 
To date, no one has reported any information in regards to wild type AnAcs distribution as well as how this distribution may or may not be affected after silencing. The goal of future gene silencing experiments would be to knockdown certain enzymes expressed in the plants glandular trichomes and compare AnAcs distribution in RNAi exposed plants and plants not exposed to RNAi.

Enzymes play a vital role in the production of plant metabolites. Currently, not all of the enzymes responsible for the production of AnAcs in geranium plants are known conclusively. However, current understanding of AnAcs production has suggested a few key enzymes. In an effort to test to see if these suggested enzymes do in fact play a role in the production of AnAcs, gene knockdown studies have been proposed. Although gene knockdown is not the focus of this work, the focus of this work is to be able to develop a method to distinguish between wild type geraniums and those experiencing gene knockdown.

This thesis focuses on the imaging of AnAcs on geranium leaves. First, the possibility of using AnAcs as fluorescent probes for fluorescence imaging is discussed in Chapter 2. Chapter 2 also addresses the challenges encountered in our first application of MALDI-MSI for imaging AnAcs. Chapter 2 concludes with the successful results obtained in the imaging of AnAcs. Finally, this thesis ends with overall conclusions of this work and the directions for future research. 


\section{CHAPTER 2}

\section{Fluorescence Studies}

\section{Introduction and Background}

As stated earlier, fluorescence (FL) imaging is a powerful technique used to study biological processes such as cell development, disease progress, cell signaling, etc. Furthermore, since a typical fluorophore contains a conjugated pi system, like a benzene ring, and anacardic acids (AnAcs) fulfill this requirement, the possibility of using them for fluorescence imaging was investigated. After thorough literature searches, we found no previous studies investigating the fluorescence of AnAcs. However, as previously stated, Gerhold et. al. (1984) investigated the UV-Vis absorption properties and determined the wavelengths of maximum absorption to be $208 \mathrm{~nm}$ and $308 \mathrm{~nm}$. The first objective of this project was to determine the optimal fluorescence excitation and emission wavelengths for AnAcs in ethanol. Secondly, the possibility of in situ FL imaging of AnAcs was investigated.

\section{Methods Employed}

Two stock solutions were prepared by dissolving $7.7 \mathrm{mg}$ of AnAc $\left(24: 1^{\omega 5}\right)$ in $2.25 \mathrm{~mL}$ of ethanol and $3.5 \mathrm{mg}$ of AnAc $\left(22: 1^{\omega 5}\right)$ in $1 \mathrm{~mL}$ of ethanol. Based on the emission spectrum of salicylic acid (Figure 7), the emission wavelength was 


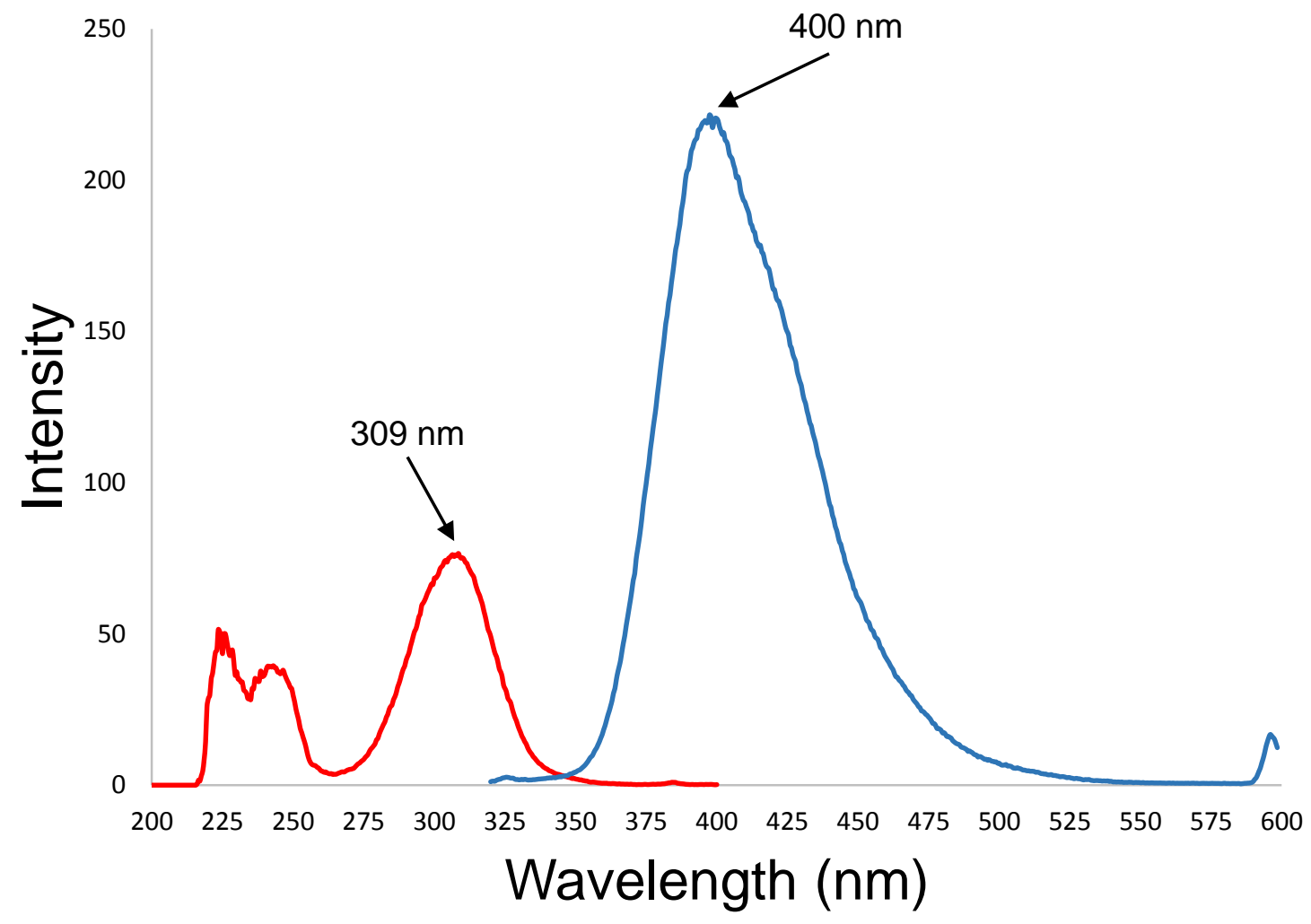

Figure 7: Excitation (red) and emission (blue) spectra of salicylic acid. 
set at $420 \mathrm{~nm}$. To acquire the excitation spectrum, the excitation wavelength was scanned from 200 to $400 \mathrm{~nm}$. Once the wavelength of maximum excitation was

determined $\left(24: 1^{\omega 5}, \lambda_{\mathrm{ex}}=296 \mathrm{~nm}, \mathrm{n}=3\right)$, an emission spectrum was obtained by scanning the emission wavelength from 375 to $600 \mathrm{~nm}$.

\section{Results and Discussion}

The maximum wavelength of excitation of both AnAcs was determined to be $294 \mathrm{~nm}(\mathrm{n}=3)$ (Figure $8 \mathbf{a}$ and $\mathbf{b})$. Although this value is a few $n m$ lower than the previously reported value of $308 \mathrm{~nm}$ (Gerhold et al., 1984), it is still within the plateau of maximum absorption in the UV-Vis spectrum. The wavelength of maximum emission was found to be 402 and $400 \mathrm{~nm}$ for 22:1 ${ }^{\omega 5}$ and $24: 1^{\omega 5}$, respectively (Figure $8 \mathbf{a}$ and $\mathbf{b}$ ). The fluorescence is most likely to be emitted after the $n \rightarrow \pi^{*}$ transition involving the "n" electrons of the oxygen atoms and the conjugated pi system of the benzoic ring. This is further supported by the fact that 2-hydroxybenzoic acid (salicylic acid) has the same maximum excitation and emission wavelengths as both AnAcs. The only chemical difference between salicylic acid and AnAcs is the presence of a hydrocarbon tail in the $6^{\text {th }}$ position of the benzoic ring of AnAcs. Lastly, since the double bond in both $22: 1^{\omega 5}$ and $24: 1^{\omega 5}$ does not contribute to the conjugation of the pi system, there is no difference in fluorescence between the two molecules thus making it difficult to distinguish them via fluorescence imaging. 

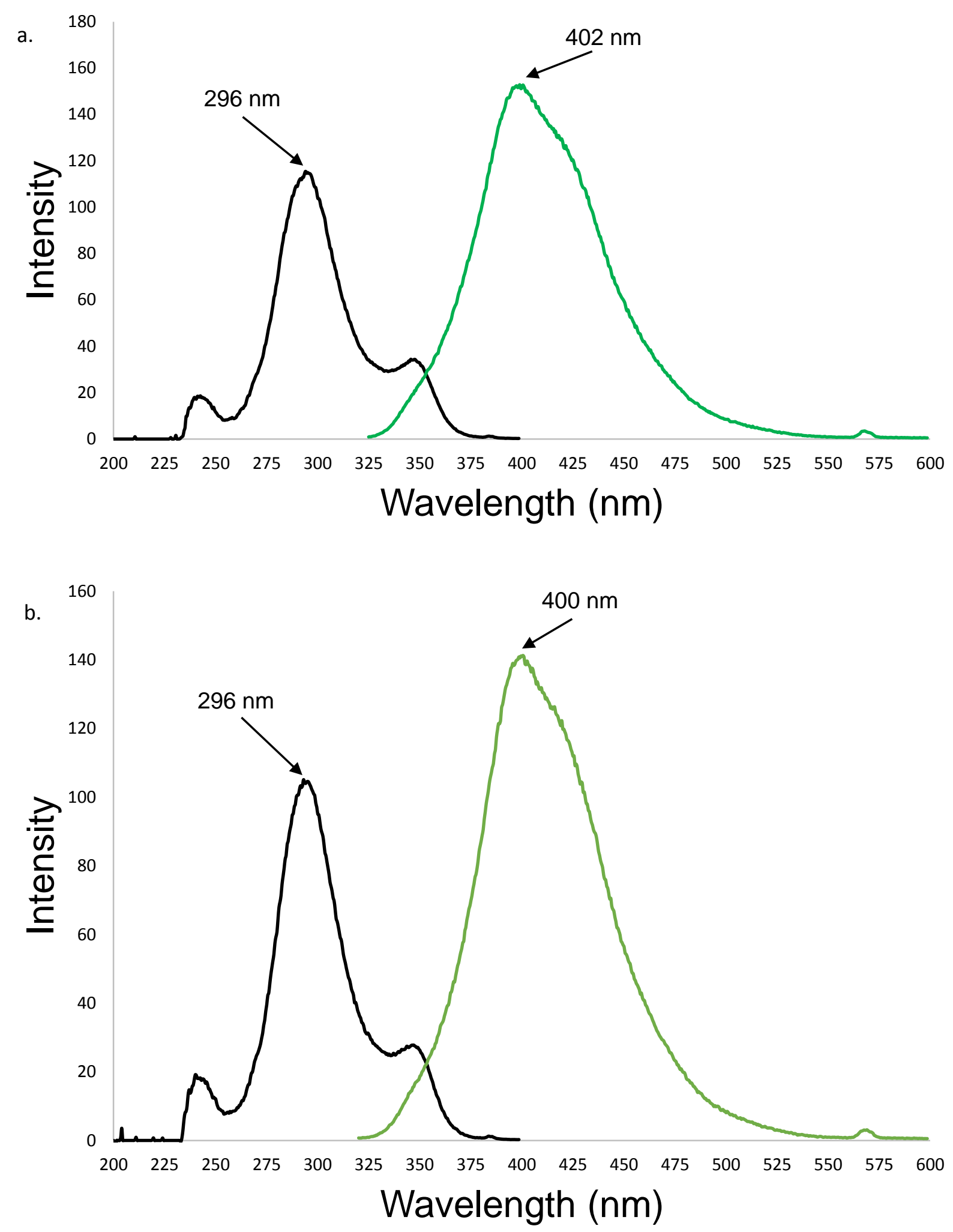

Figure 8: (a) Excitation (black) and emission (green) spectra of 22:1 ${ }^{\omega 5}$ AnAc. (b) Excitation (black) and emission (green) spectra of $24: 1^{\omega 5}$ AnAc. 
Conclusion

Based on the data analysis, the wavelengths of maximum FL excitation and emission for AnAcs in ethanol were determined to be 294 and $~ 400 \mathrm{~nm}$, respectively. The main goal of this work was to explore the possibility of using AnAcs as fluorescence probes for imaging. However, it can be concluded that AnAcs are not useful fluorescence probes because the excitation and emission wavelengths overlap with many of those corresponding to biological molecules as seen in Figure 9 below (Ramanujam, 2006). Importantly, since fluorescence is not able to distinguish amongst various AnAcs, it would not be a useful technique to identify different geranium species based on their AnAcs profiles.

\section{Matrix Assisted Laser Desorption lonization Mass Spectrometry Imaging (MALDI-MSI)}

In the mid 1990's and into the early 2000's, various laboratories demonstrated the effectiveness of MALDI-MSI that ultimately led to the widespread use of MALDI-MSI as a powerful method for analysis of various biological tissues. In 1995, MALDI-MS was first used to generate 3-D "images" and contour plots of thin-layer chromatograms (Gusev, Vasseur, Proctor, Sharkey, \& Hercules, 1995). Soon after, in 1997, Caprioli et al. (1997) demonstrated the ability to generate ion images of biological tissue using MALDIMS. Furthermore, in 2000, Garden and Sweedler used MALDI-MSI to reveal the heterogeneity of the matrix distribution and its impact on the appearance of mass spectral data (Garden \& Sweedler, 2000). 


\begin{tabular}{|lll|}
$\begin{array}{l}\text { Endogenous } \\
\text { Fluorophores }\end{array}$ & $\begin{array}{l}\text { Excitation Maxima } \\
(\mathrm{nm})\end{array}$ & $\begin{array}{l}\text { Emission Maxima } \\
(\mathrm{nm})\end{array}$ \\
\hline Tryptophan & 280 & 350 \\
\hline Tyrosine & 275 & 300 \\
\hline Phenylalanine & 260 & 280 \\
\hline Collage & 325 & 400,405 \\
\hline Elastin & 290,325 & 340,400 \\
\hline Phospholipids & 436 & 540,560 \\
\hline
\end{tabular}

Figure 9: Excitation and emission maxima of common cellular components (Ramanujam, 2006). 
In 2002, Spengler et al. were able to use MALDI-MSI to generate ion images with spatial resolutions between $0.6 \mu \mathrm{m}$ and $1.5 \mu \mathrm{m}$ (Spengler \& Hubert, 2002). In MALDI-MSI, the spatial resolving power or spatial resolution depends on the choice of matrix and the homogeneity of its distribution over the sample surface, stepper motor accuracy, and laser spot size (Gode \& Volmer, 2013). While stepper motor accuracy and laser spot size are variables restricted by the instrument itself, the choice of matrix is not. The main focus for the rest of the thesis is to address the challenges in acquiring MALDI-MS images of AnAcs on the surface of geranium leaves and the achievements that were made.

Introduction and Background

\section{MALDI-MSI}

Since Caprioli et al. (1997) pioneered the use of MALDI to generate ion images of peptides and proteins in biological tissue, MALDI imaging has expanded enormously. Today, the technique has evolved into a powerful tool for studying the distribution of metabolite and drugs in animals and bacteria, (Solon et al., 2010; Watrous \& Dorrestein, 2011) in situ lipid profiling (Rujoi, Estrada, \& Yappert, 2004), and the distribution of metabolites and agrochemical compounds in plants (Burrell, Earnshaw, \& Clench, 2007; Hamm et al., 2010; Mullen, Clench, Crosland, \& Sharples, 2005). The main difference between MALDI-MSI experiments and traditional MALDI-MS experiments is data acquisition and handling. Currently, MALDI-MSI is a fully automated process with newer instruments having imaging software built-in. However, some older instruments 
may require software developed by a third party to automate the acquisition and data compiling process. Older studies required manual data acquisition and image construction (Rujoi et al., 2004).

As mentioned in Chapter 1, a MALDI-MS image is generated from a large number of mass spectra generated by rastering the laser over the sample placed in the ionization chamber. A major advantage of MALDI-MSI is the ability to discern the distribution of multiple analytes from a single image, as seen in Figure 10 below (Solon et al., 2010). Furthermore, MALDI-MSI does not require labeling. One major drawback to MALDI-MSI is that it only gives qualitative information on analyte distribution because of differences in the ionization efficiency of various analytes, tissue specific ion suppression, matrix choice, and homogeneity of the matrix distribution (Stoeckli, Staab, \& Schweitzer, 2007). However, relative amounts of AnAcs can be determined by direct comparison of peak intensity since AnAcs are expected to have the same ionization efficiency. In order to obtain more precise quantitative information, it would be necessary to use known amounts of internal standards with ionization efficiencies comparable to those of the analytes of interest.

\section{Sublimation of para-Nitroaniline}

In 1988, Viswanadham and Hercules used PNA in MALDI MS experiments to investigate ion-molecule reactions of aromatic nitro compounds (Viswanadham, Hercules, Schreiber, Weller, \& Giam, 1988). In the 1990's, more papers were published describing the use of PNA as a MALDI matrix 


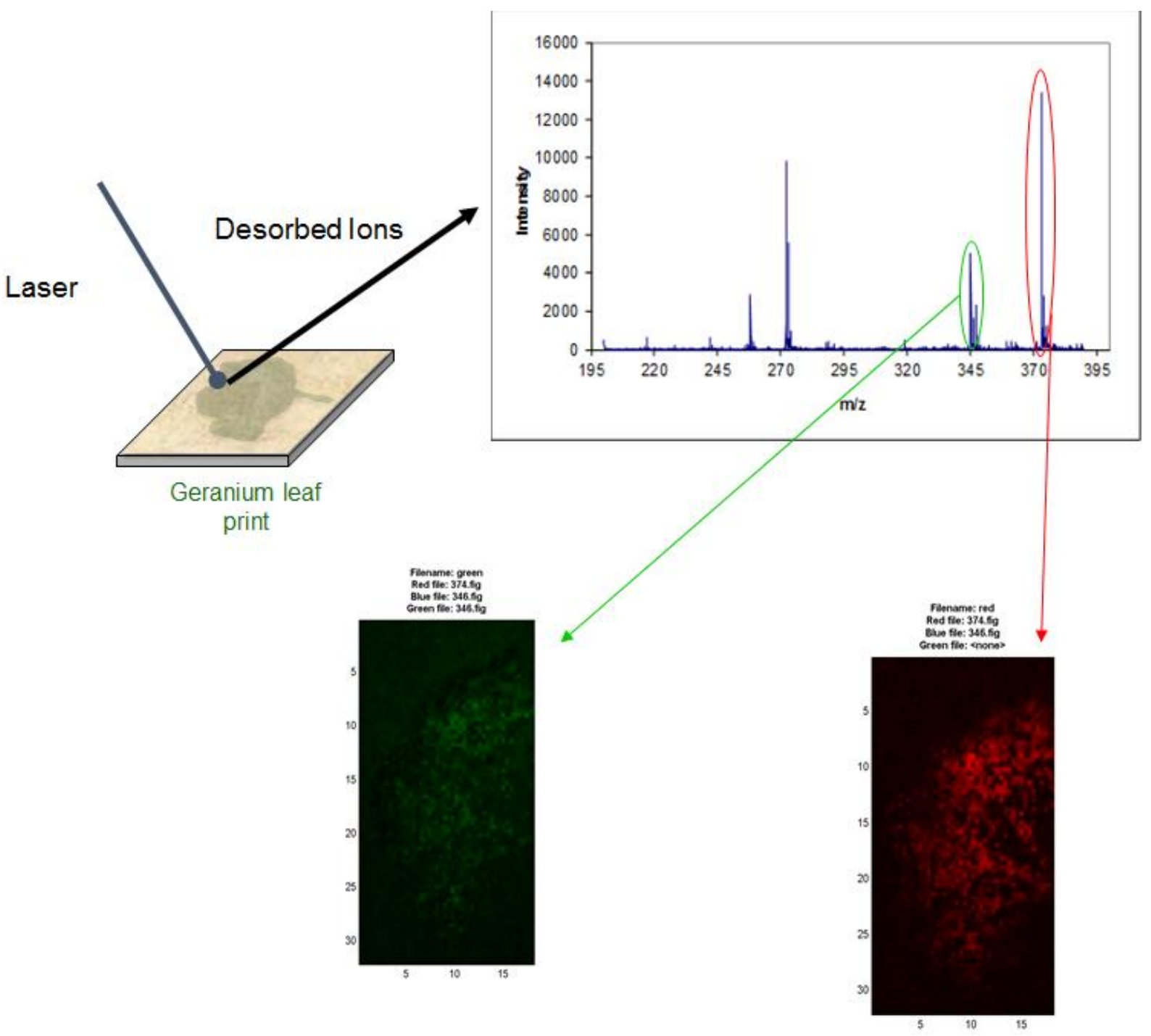

Figure 10: Generation of different ion images from the same location. 
(Fitzgerald, Parr, \& Smith, 1993; Marto, White, Seldomridge, \& Marshall, 1995;

Salih \& Zenobi, 1998). In 2004, Estrada et al. reported the use of PNA for the analysis of lipids in porcine and bovine eyes (Estrada \& Yappert, 2004).

However, despite the good S/N ratio obtained as a result of using PNA as a matrix, PNAs high vapor pressure leads to rapid sublimation under the high vacuum conditions of typical MALID instruments used for MSI (Astigarraga et al., 2008). Thus, PNA is not a suitable matrix for experiments that require long acquisition times such as MSI experiments (Fernandez, Ochoa, Fresnedo, Giralt, \& Rodriguez-Puertas, 2011).

\section{Methods}

\section{1) Materials}

The matrix compound 4-nitroaniline (PNA) was purchased from Aldrich Chemical Co., Inc. (Milwaukee, WI). Furthermore, the matrix compounds bis( $\mathrm{p}$ nitrophenyl) amine (BNPA) and 2,5-dihydroxyacetophenon were purchased from TCI America (Portland, OR). The additive, heptafluorobutyric acid (HFBA) was purchased from Alfa Aesar (Ward Hill, MA). Ethanol and plant material were provided by Professor David Schultz, Ph.D. (University of Louisville, Biology Department). The plants were grown at $21^{\circ} \mathrm{C}$. The lighting conditions were kept constant at $\sim 125 \mathrm{umol} / \mathrm{m}^{2} / \mathrm{s}$ with a 16 hour light/ 8 hour dark cycle. Crude AnAcs were isolated/purified (as described in Chapter 1) and provided by Professor David Schultz, Ph.D. (3-aminopropyl)triethyoxysilane (APTES) was provided by Professor Francis Zamborini, Ph.D. lab (University of Louisville. Chemistry Department). All reagents were used without further purification. 


\section{2) Matrix Preparation and Deposition}

Preliminary experiments were carried out using PNA as the matrix while the imaging experiments were conducted using BNPA. For PNA, a $0.17 \mathrm{M}$ solution was prepared in $95 \%$ ethanol and BNPA was prepared as a $1.25 \mathrm{mg} / \mathrm{mL}$ solution in $95 \%$ ethanol. In some experiments, additives were added to the PNA solution in an effort to increase the vacuum stability; these exceptions will be clearly noted.

In all cases, the matrix was deposited onto the MALDI plate via a "dipping" method. Briefly, a $10 \mathrm{~mL}$ solution of matrix was prepared in a $15 \mathrm{~mL}$ conical vial. After sonication, with heat for $\sim 15 \mathrm{~min}$, the solution was poured into a sterile Petri dish. The surface of the MALDI plate was dipped into the solution and then removed. Upon removal of the plate, a heat gun was immediately held above the plate to ensure rapid evaporation of the solvent and a homogenous matrix coating. Figure 11 below depicts the matrix deposition technique just described. After matrix coating, the plate was ready for deposition of AnAcs from tissue via a modified analyte transfer technique.

\section{3) Tissue Preparation}

Fresh picked geranium leaves were obtained from growth chambers or greenhouse maintained by the Schultz lab (University of Louisville, Biology Department). Leaves were handpicked from geranium plants and transported in a sterile Petri dish where they were stored for analysis on the same day. Leaves 

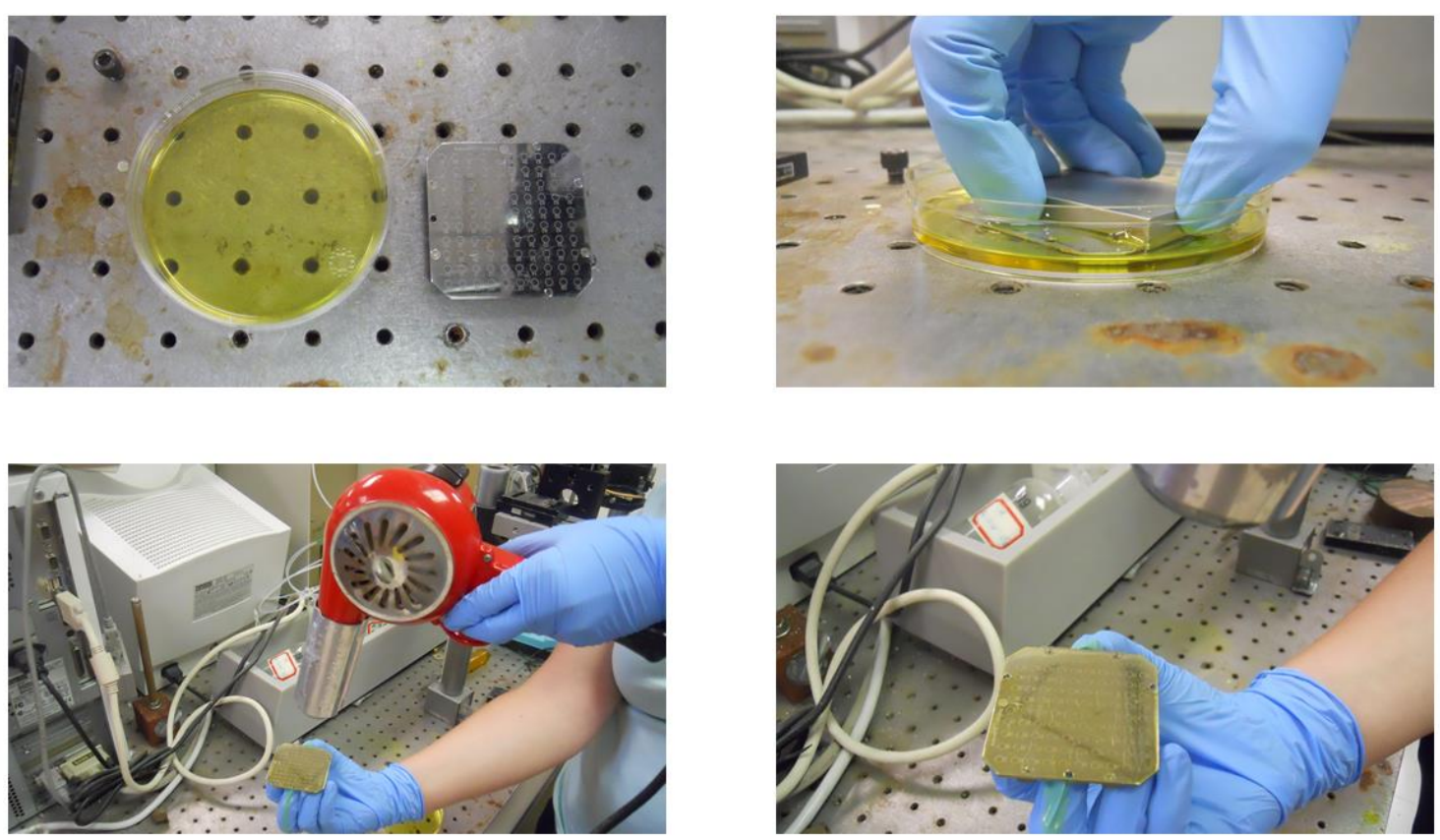

Figure 11: (a) MALDI plate lying next to Petri dish containing the matrix solution (1.25 mg BNPA/mL ethanol). (b) MALDI plate turned upside down and dipped into matrix solution. (c) Evaporation of the solvent from above the MALDI plate with a heat gun. (d) Homogenous coating of MALDI plate with matrix. 
smaller than the dimensions of the MALDI plate were selected so whole tissue analysis could be carried out.

Since AnAcs are surface metabolites, analyte transfer was achieved by placing the leaf on a pre-coated MALDI plate and applying a force in the direction perpendicular to the MALDI plate for $\sim 10 \mathrm{~min}$. There was no special tissue preparation technique (drying, labeling, etc.) required before AnAcs transfer and analysis. One major drawback to this technique is that the leaf surface is not always flat and, therefore the efficiency of AnAcs transfer is affected by the leaf topology. Figure 12 below shows a diagram depicting the AnAcs transfer technique employed for all imaging experiments.

\section{4) MALDI-TOF MSI Data Acquisition and Treatment}

Negative ion images were acquired using a Voyager Biospectrometry DE workstation (Applied Biosystems, Foster City, CA) operated in the reflector mode. The negative mode was used because it gave the best $\mathrm{S} / \mathrm{N}$ ratio for the detection of AnAcs. The mass spectrometer utilizes a pulsed nitrogen laser $(337 \mathrm{~nm})$ for sample ionization. A $20 \mathrm{kV}$ extraction voltage was applied after a $70 \mathrm{~ns}$ delay. The laser power was adjusted to maximize the signal-to-noise ratio $(\mathrm{S} / \mathrm{N})$ while minimizing fragmentation.

For imaging experiments, the instrument was run in automatic mode using MALDI MS Imaging Tool (MMSIT) (Novartis, Markus Stoeckli, Ph.D.,

Switzerland). Laser spot size is $\sim 100 \mu \mathrm{m}$ but the laser step size was set to 400 $\mu \mathrm{m}$ and the spectrum for each pixel represents the average of 25 acquired mass 


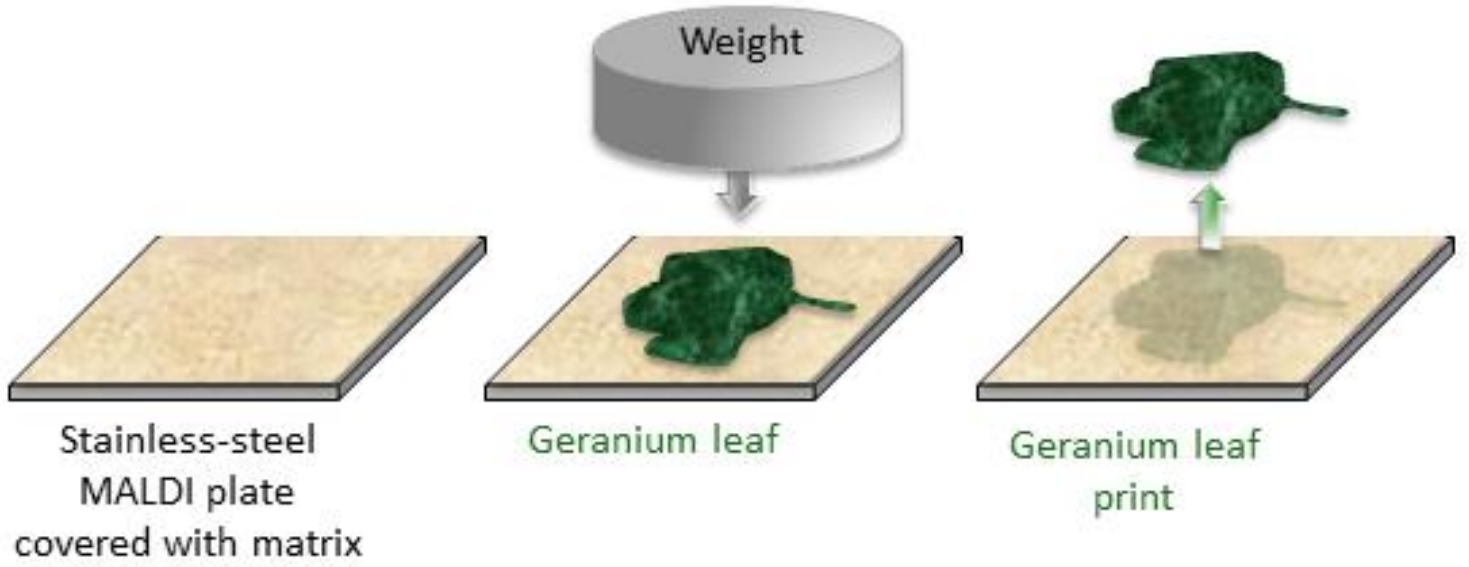

Figure 12: Pictorial description of the printing method used to transfer the AnAcs from the surface of the leaf to the MALDI plate coated with matrix. 
spectral traces. These parameters were chosen because they gave satisfactory resolution while maintaining both reasonable acquisition time ( $24 \mathrm{hrs}$.) and data size. Using MMSIT, users can select the area of interest to be scanned as well as laser step size. Furthermore, MMSIT takes the dat files generated by the Voyager instrument and converts them to the format needed (e.g., .img, .t2m, and .hdr) for post analysis image processing. To overcome the challenge of large data files, the imaging of a single leaf was done by imaging the left and right halves of the leaf separately.

After data acquisition, the image analysis was done using TissueView ${ }^{\mathrm{TM}}$ (AB Sciex, Framingham, MA). TissueView displays spatial localization and intensity of $\mathrm{m} / \mathrm{z}$ values of interest. Furthermore, TissueView allows for the generation of single images based on a single $\mathrm{m} / \mathrm{z}$ value, co-registration of images, and mass spectral information corresponding for each pixel.

\section{Results and Discussion}

\section{1) Matrix Selection}

As mentioned in the background section, para-nitroaniline (PNA) is an organic compound that contains a nitro group and an amine group in the para positions of a benzene ring (see Figure 13 below). The wavelength of maximum absorption of PNA is $380 \mathrm{~nm}$, which is close to the wavelength of the $\mathrm{N}_{2}$ lasers commonly found in MALDI instruments (Hemker \& van Dam-Mieras, 1983). Even though PNA is an effective matrix for both positive and negative modes, it 


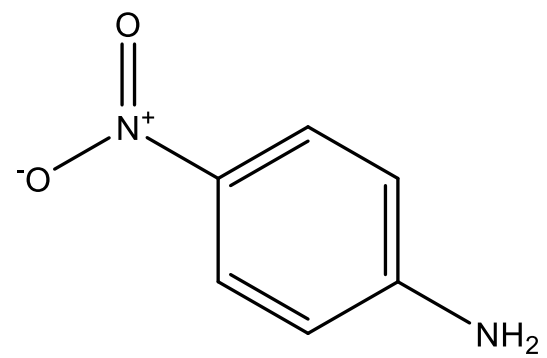

4-nitroaniline

Figure 13: Structure of 4-nitroaniline (PNA). 
sublimes and cannot be used for studies that require lengthy acquisition times (Fernandez et al., 2011).

Results

Although PNA was known to sublime under high vacuum, experiments were carried out in order to increase the lifetime of PNA in vacuum. As seen in the Figure 14 below (PNA only image), PNA sublimes rather quickly (20 minutes or less) under high vacuum. One attempt to increase vacuum stability was by the addition of $0.1 \%$ heptafluorobutyric acid (HFBA). In 2010, Colsch et. al. used HFBA as an additive to improve the vacuum stability of another matrix, 2,6dihydroxacetophenone (2,6-DHA) known to sublime (Colsch, Jackson, Dutta, \& Woods, 2011). Figure 15 below shows a spectrum of the PNA/HFBA/crude 24:1 ${ }^{\omega 5}$ AnAc mixture right after inserting the plate into the instrument. However, the relative peak intensity for PNA after $\sim 1 \mathrm{hr}$. decreased, thus suggesting that PNA was still subliming. This was further confirmed visually by examining the matrix coating before and after analysis.

A second approach that was tried in order to improve the vacuum stability of PNA under vacuum was by coating the plate in (3-aminopropyl) triethyoxysilane (APTES). Figure 16 below shows the structure of APTES. The hypothesis was that the silane portion of the molecule would bind to the stainless steel surface leaving the amine portion exposed and able to interact with the nitro group of PNA thus reducing its sublimation. To ensure that the surface of the MALDI plate was clean to enhance binding of APTES, the MALDI plate was sonicated in an acetone bath for five minutes followed by sonication in an ethanol 

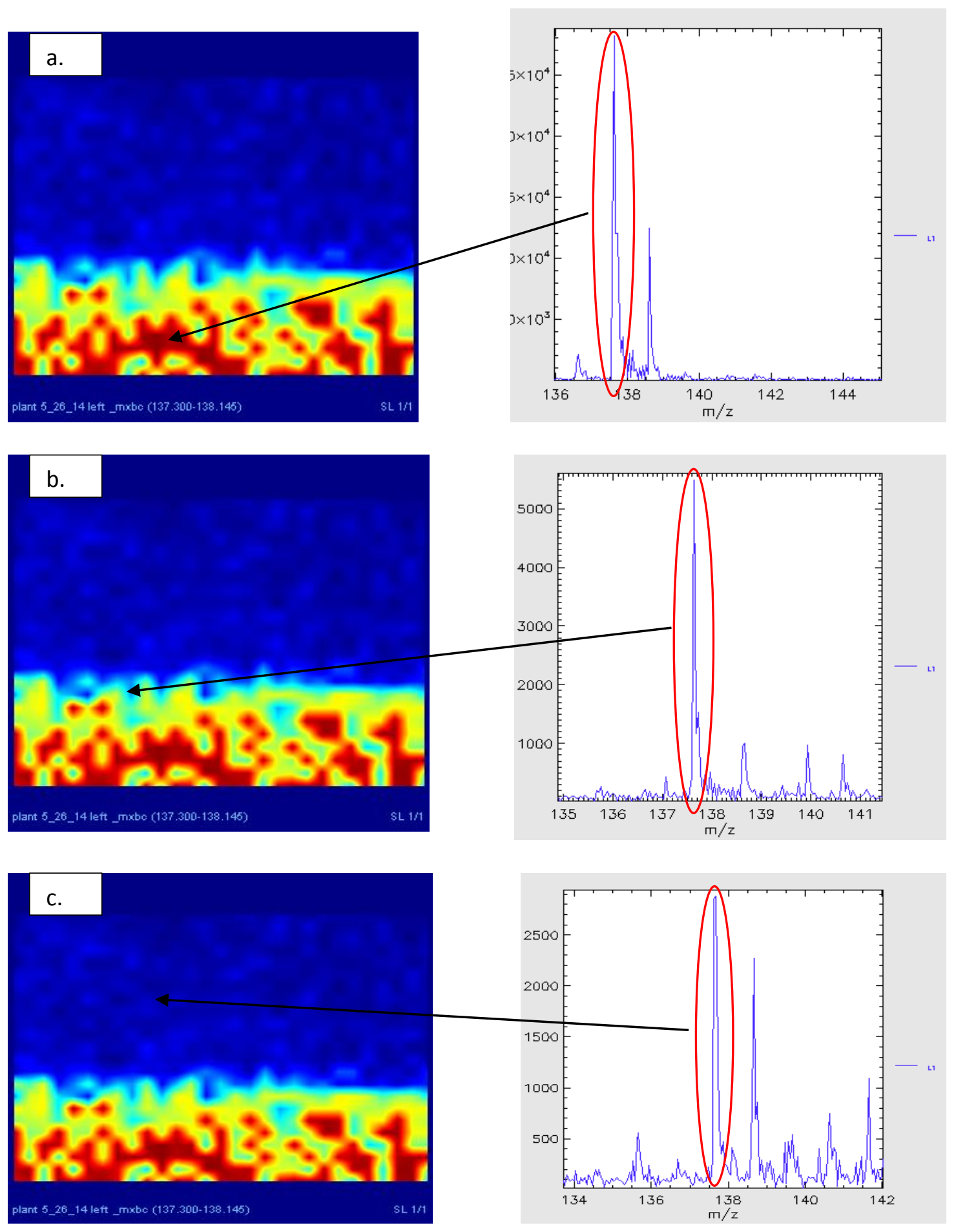

Figure 14: MSI (left) and MS data (right) of a MALDI plate coated in PNA only. Spectra collected from (a) bottom (no or little sublimation) of the plate, (b) middle of the plate, and (c) top (significant sublimation) of the plate. The peak circled peak corresponds to (PNA-H) - The acquisition time for each ion image increases from the bottom to the top. 


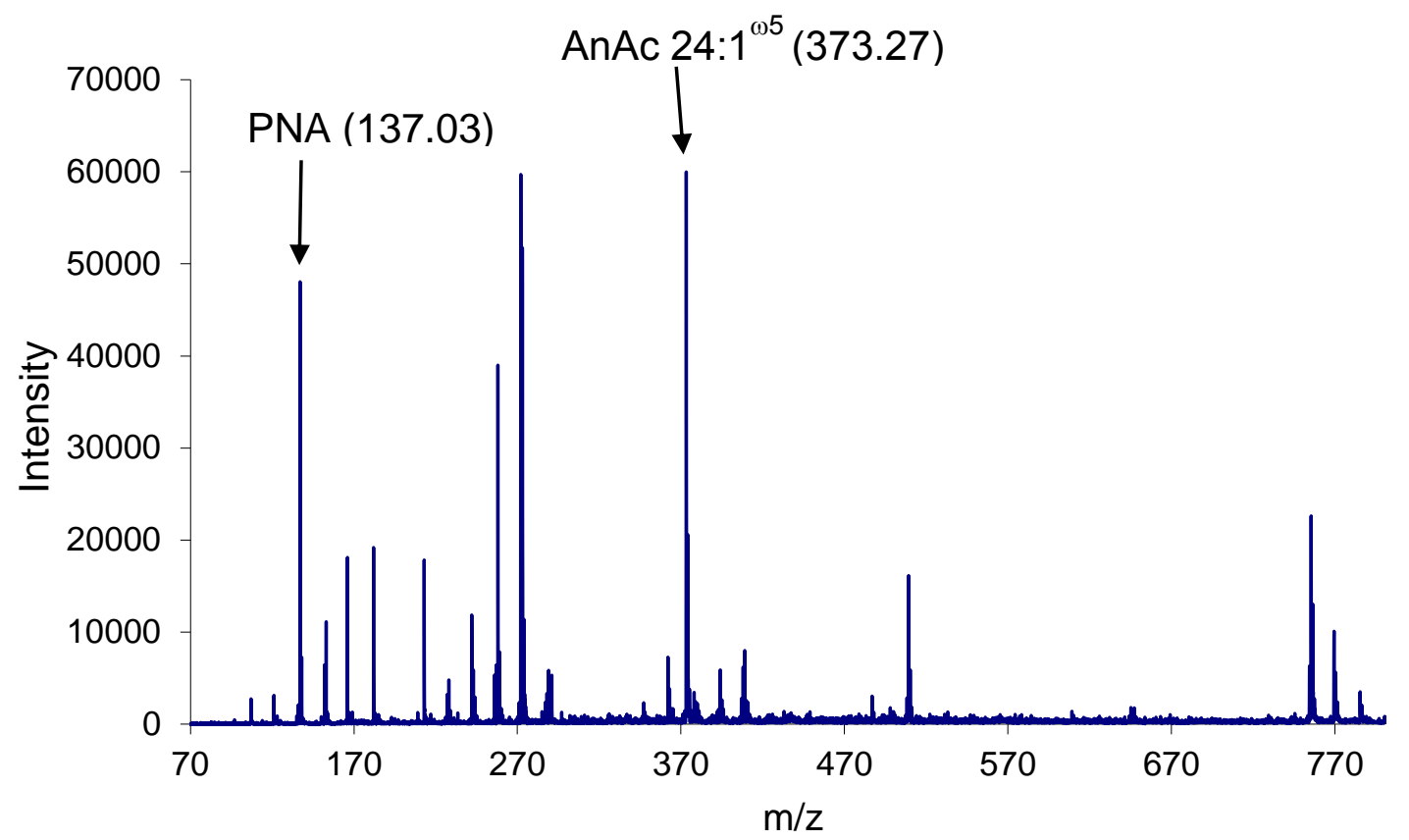

Figure 15: Mass spectrum PNA and 0.1\% HFBA spotted with AnAc 24:1w5. The spectrum was collected immediately after the plate was inserted into the low vacuum MALDI chamber. 


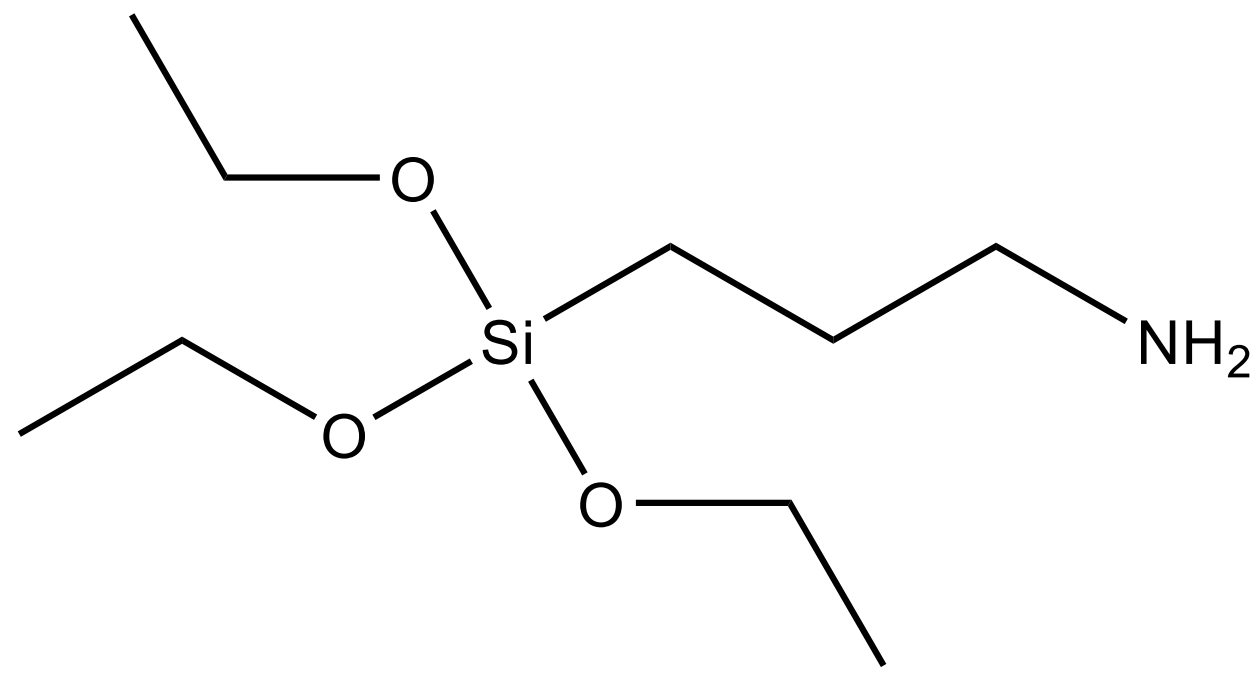

Figure 16: Molecular structure of (3-aminopropyl)triethyoxysilane (APTES). 
bath for another five minutes. Next, $2 \%, 5 \%$, and $10 \%$ APTES solutions were prepared in a 3:1 ethanol/water solution and stirred at room temperature for 10 minutes. Lastly, the APTES was deposited onto the MALDI plate via spin coating at $\sim 1,500 \mathrm{rpm}$. After spin coating, the surface was cured by placing the plate into an oven for 1 hour at $130^{\circ} \mathrm{C}$ and then briefly washed with distilled water (Rezaei, Havakeshian, \& Ensafi, 2013). After data acquisition, it was evident that the outer most layer of PNA sublimed while the layer directly in contact with APTES was bound, but that amount was insufficient to yield data with good $\mathrm{S} / \mathrm{N}$.

In 1996, Kraus et al. (1996) achieved very good resolution and sensitivity in the negative mode of MALDI using 2,5-dihydroxyacetophenone (2,5-DHA) thus this was pursued as a possible matrix for imaging AnAcs (Figure 17). However, like the 2,6-DHA isomer, 2,5-DHA sublimes under high vacuum leading to poor S/N (H. Y. Wang, Jackson, \& Woods, 2007).

While investigating PNA under high vacuum conditions, a peculiar peak was observed both before and after the PNA sublimed. In order to uncover the identity of this peak, a MALDI plate was coated with PNA using the "dipping" method and inserted into the instrument to be left overnight. As soon as possible, a sample spectrum was collected once the plate was inside the high vacuum instrument (Figure 18a). After $\sim 24$ hours of being subjected to high vacuum, another sample spectrum was collected (Figure 18b). The $\mathrm{m} / \mathrm{z}$ value of 137.0345 (corresponding to (PNA-H) ${ }^{-}$was the most intense peak soon after the plate was inserted; however, this peak disappeared due to sublimation and all that remained was a peak corresponding to $\mathrm{m} / \mathrm{z}$ 258.2. High resolution MS/MS 


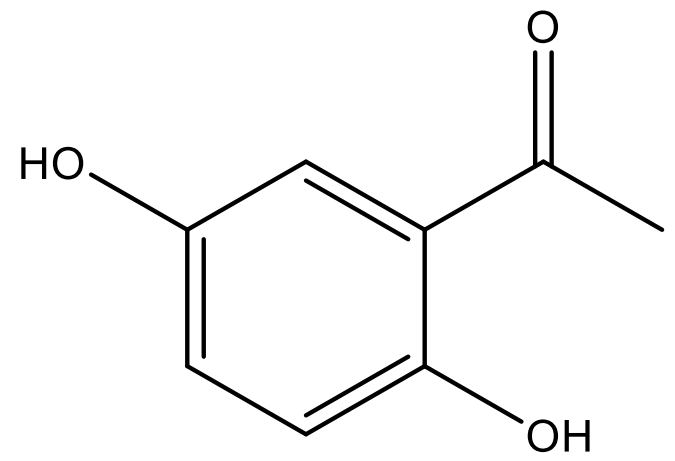

Figure 17: Molecular structure of 2,5-dihydroxyacetophenone (2,5-DHA). 
a.

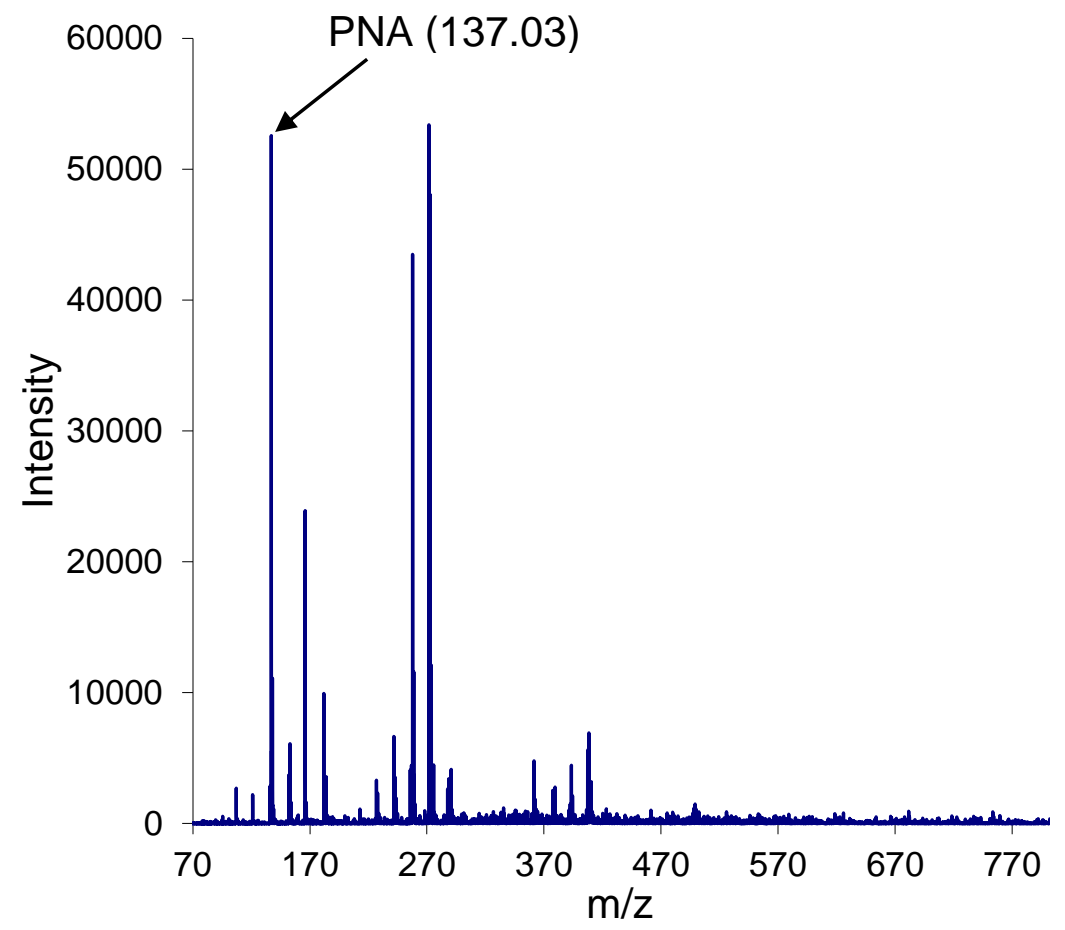

b.

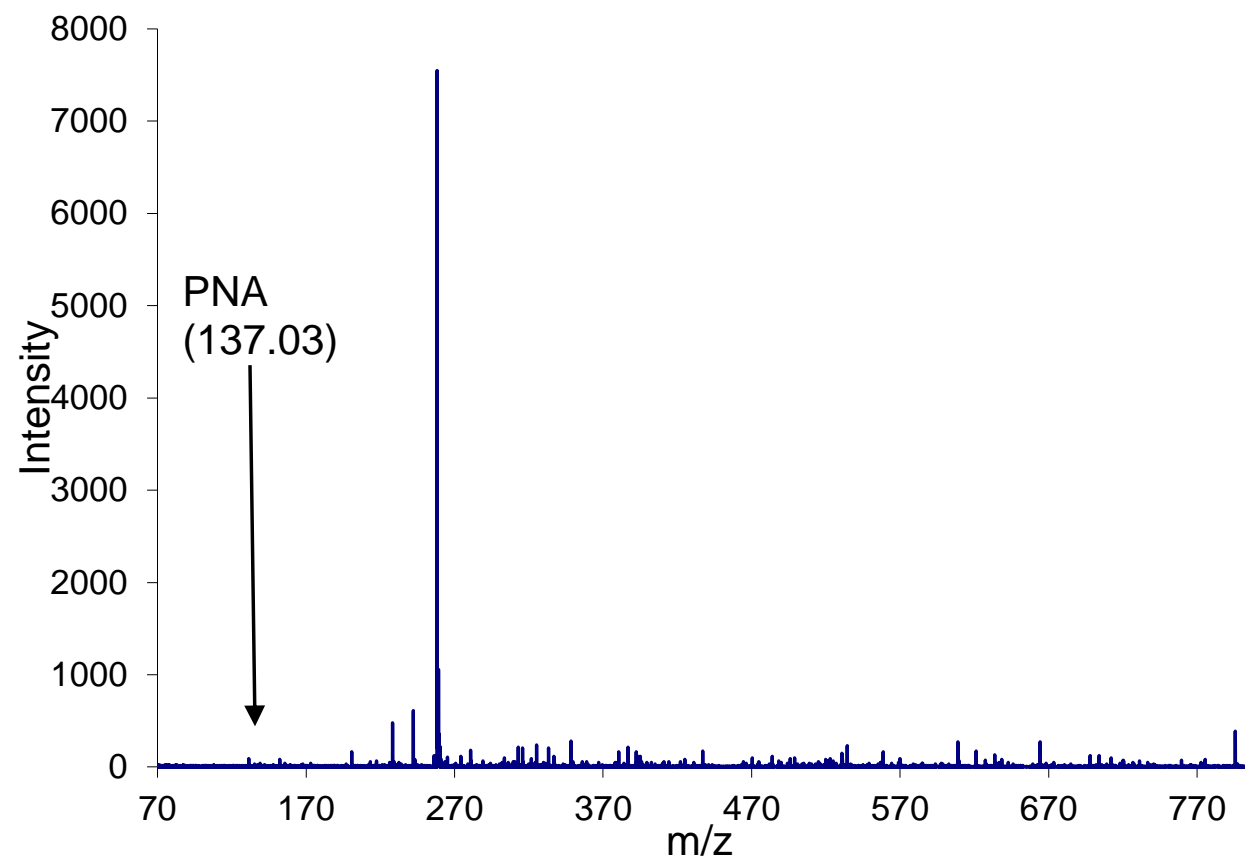

Figure 18: Mass spectra of PNA collected (a) right after and (b) 24 hrs after inserting plate into ionization source held at high vacuum levels $\left(\sim 10^{-7} \mathrm{~T}\right)$. 
experiments and literature searches lead to the conclusion that the unknown residue was bis(p-nitrophenyl)amine (BNPA)(see Figure 19). Because of the vacuum stability of BNPA and the structural similarity between BNPA and PNA, BNPA was investigated as a potential matrix for MSI of AnAcs. Once BNPA was ordered, UV-Vis data were collected and the wavelength of maximum absorption was $395 \mathrm{~nm}$ (Figure 20). This suggested that BNPA could be a potential MALDI matrix since it absorbs at $337 \mathrm{~nm}$, the wavelength of the $\mathrm{N}_{2}$ laser.

A matrix sample of $1.25 \mathrm{mg} / \mathrm{mL}$ of BNPA in $95 \%$ ethanol was prepared and deposited onto the stainless steel MALDI plate by the "dipping" method described earlier. Mass spectra of BNPA alone was collected as quickly as possible and can be seen in Figure 21a. To confirm vacuum stability, the matrixcoated plate was left in the high vacuum overnight and more sample spectra were collected the following day (Figure 21b). Based on comparison of the spectral data from figure $21 \mathrm{a}$ and $21 \mathrm{~b}$, and comparison of the signal-to-noise ratio $(\mathrm{S} / \mathrm{N})$, it can be concluded that BNPA is stable under high vacuum for at least $24 \mathrm{hrs}$. This is advantageous to MALDI-MSI experiments because some experiments can take 24 hours or more depending on the instrument, sample size, and desired spatial resolution.

To determine if BNPA was a good MALDI matrix for the detection of AnAcs, a sample of crude AnAcs was spotted for MALDI analysis using the thin layer deposition matrix mentioned in chapter 1. Briefly, a saturated solution of BNPA was spotted and allowed to dry and then a $3.4 \mathrm{mg} / \mathrm{mL}$ AnAc $\left(22: 1^{\omega 5}\right)$ in $95 \%$ ethanol solution was spotted on top of the matrix. Figure 22 below shows 


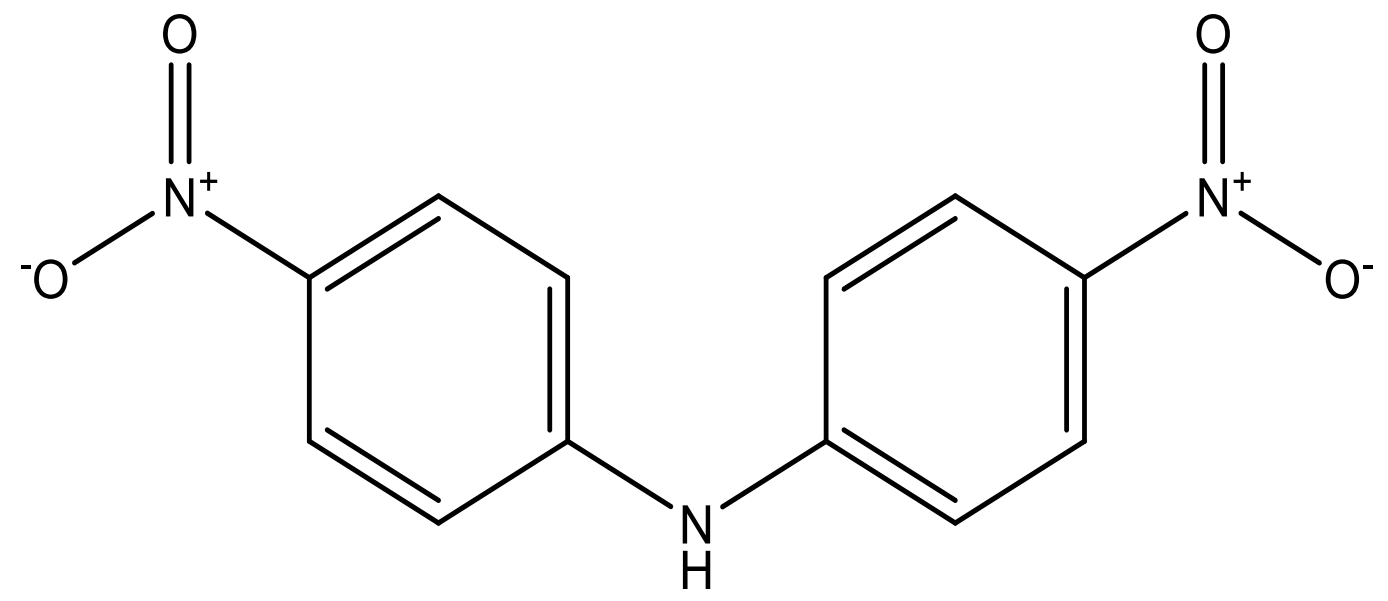

Figure 19: Molecular structure of bis( $p$-nitrophenyl)amine (BNPA). 


\section{UV-VIS BNPA (50 ug/mL)}

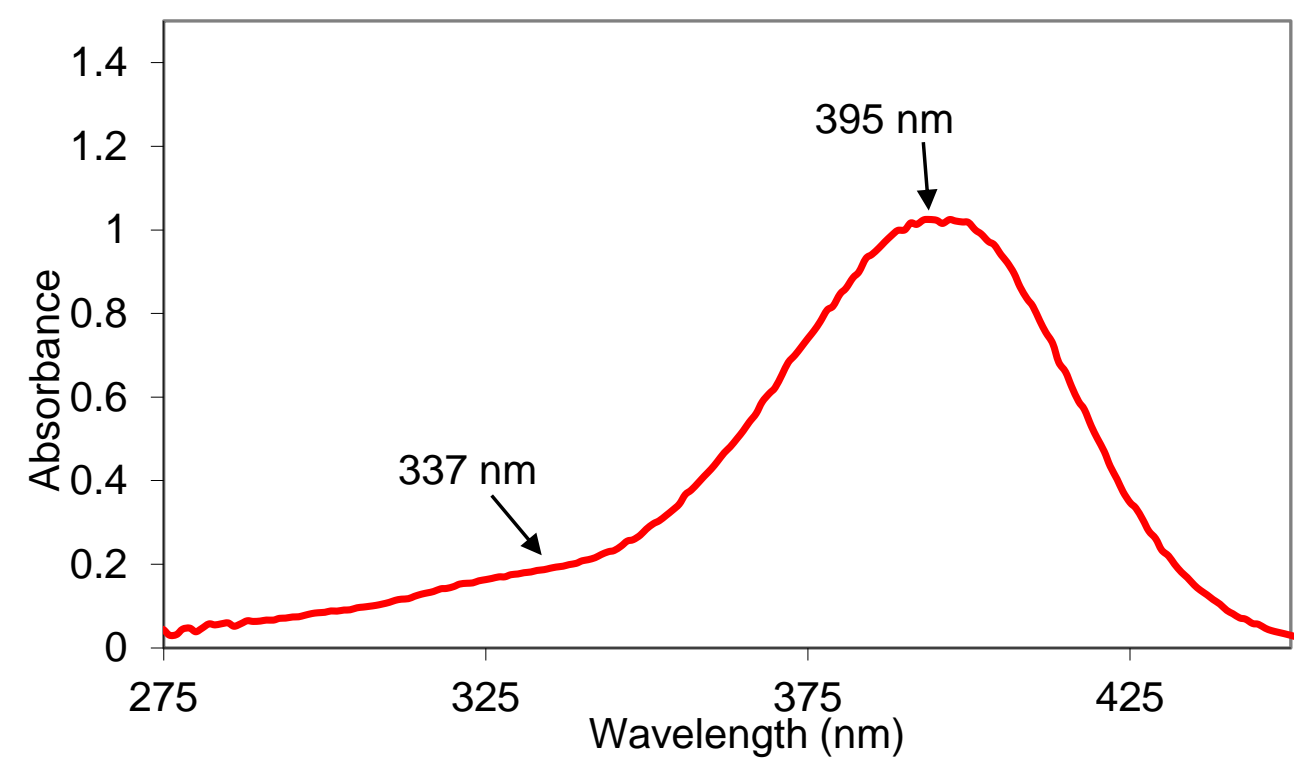

Figure 20: Absorption spectrum of bis(p-nitrophenyl)amine $(B N P A)(n=3)$. 
A

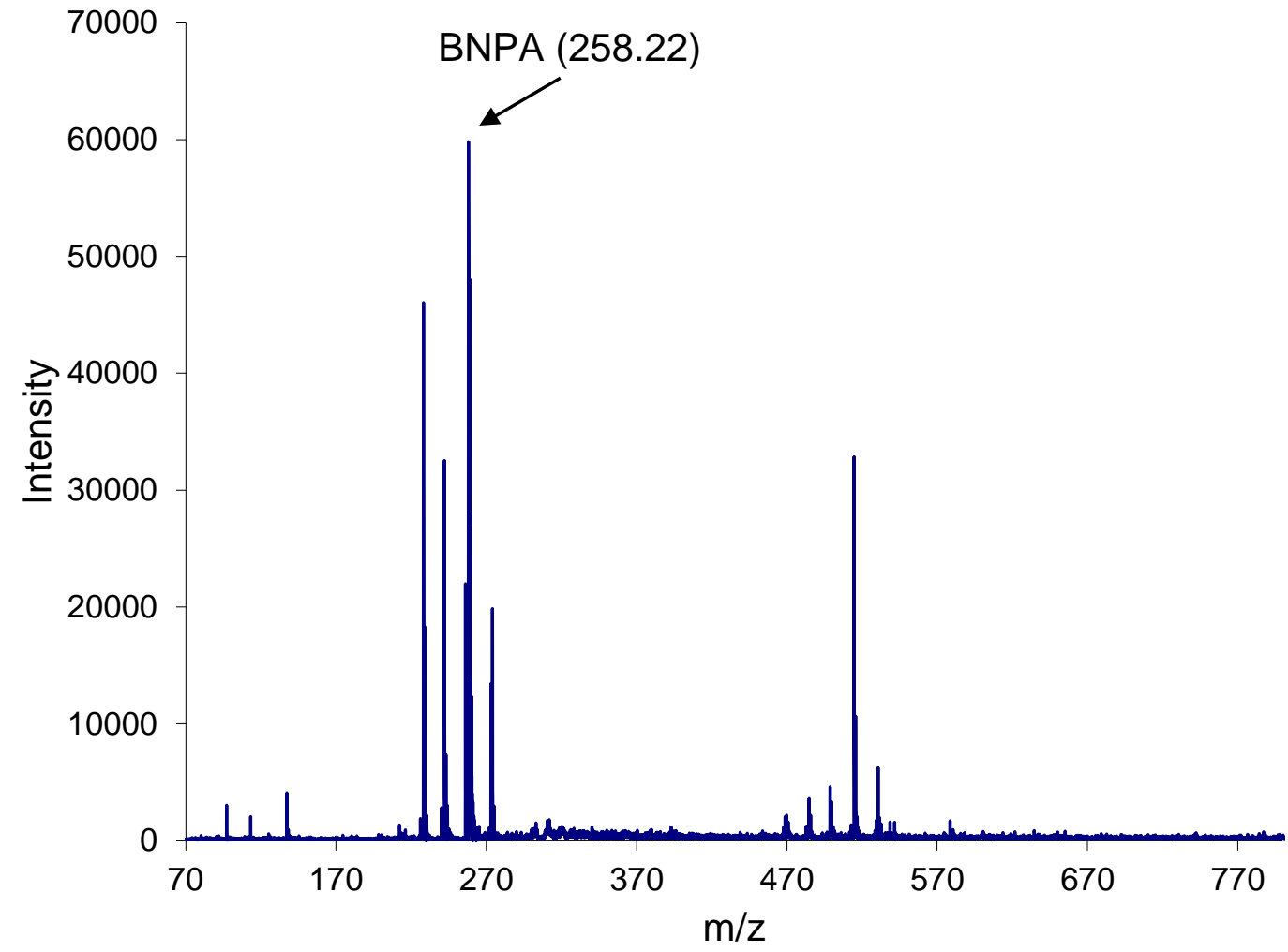


B.

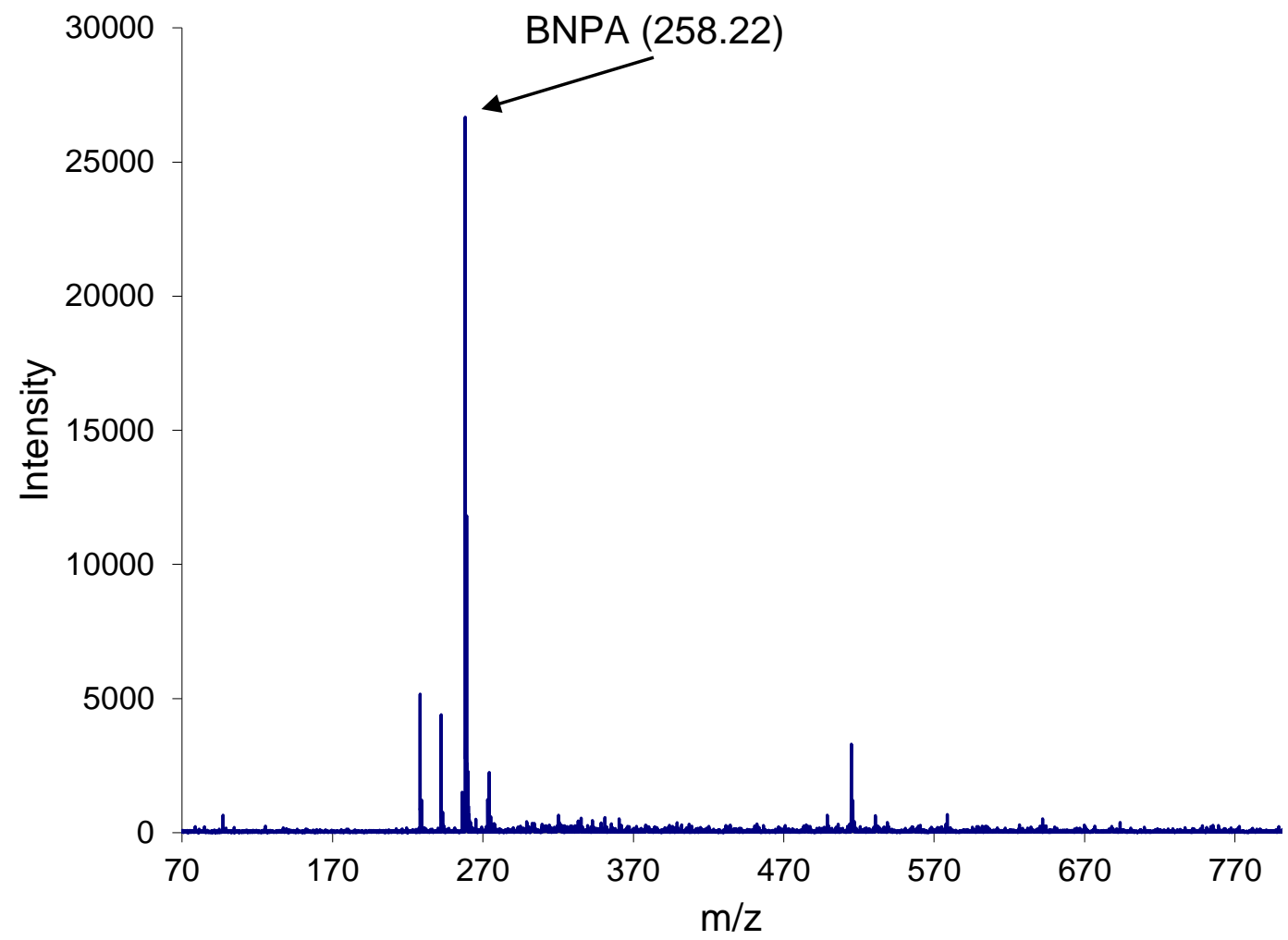

Figure 21: (a) Mass spectrum of BNPA right after inserting plate into low pressure chamber. (b) Mass spectrum of BNPA 24 after inserting plate into low pressure chamber. 


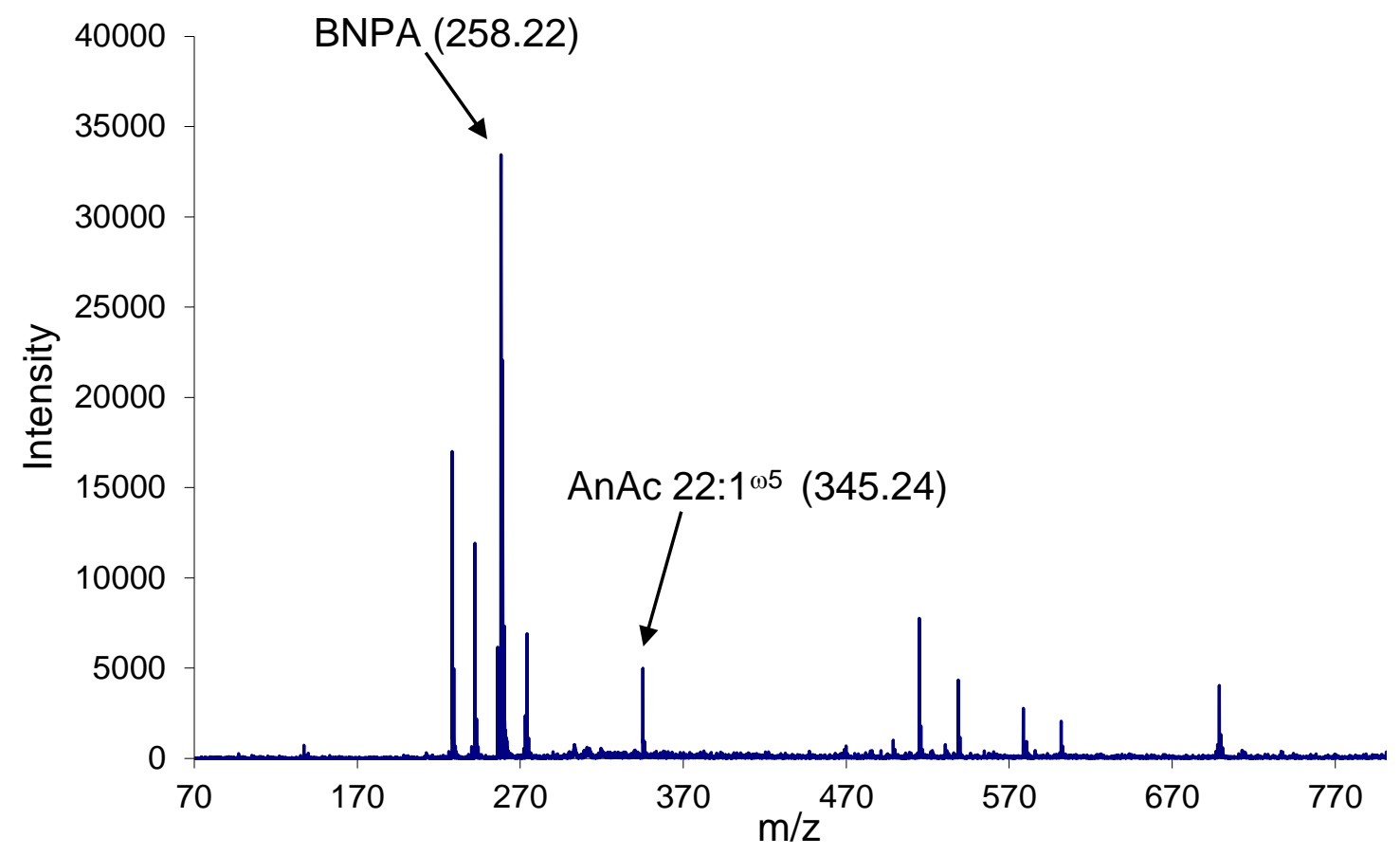

Figure 22: Mass spectrum of BNPA spotted with AnAc 22:1 ${ }^{\omega 5}$ 
the resulting mass spectrum obtained. From the data, it was concluded that BNPA is a good matrix for both imaging and detection of AnAcs in the negative mode and was thus used in all MALDI-MSI experiments.

\section{2) In situ Mass Spectral Imaging of Anacardic Acids}

As stated in Chapter 1, AnAcs are salicylic acid derivatives secreted from the glandular trichomes of geraniums. Because of their potential benefits as a therapy for various diseases and defense against pathogens, it is important to further investigate the biosynthetic pathways involved in the generation of the various AnAcs present in some plant tissues.

In 2005, Mullen et al. (2005) were the first group of researchers to demonstrate the ability of ion detection and imaging of compounds on the surface of a plant leaf or inside a plant stem using MALDI-MSI. Since then, work has been done on investigating new matrices to enhance detection of analytes in plant tissue for MALDI-MSI (Zhang, Cha, \& Yeung, 2007).

To the best of the authors' knowledge, this work represents the first demonstration of the application of MALDI-MSI to the study of AnAcs in geranium plants. The goal was to demonstrate the ability if MALDI-MSI to map the regional distribution of AnAcs $22: 1^{\omega 5}$ and $24: 1^{\omega 5}$ in geranium leaves. The accomplishment of this goal will enable future studies using gene silencing approaches to prove the identity of key enzymes involved in the synthesis of AnAcs. Furthermore, the possibility of using AnAcs profiles to differentiate between geranium species was investigated. 
One challenge when working with plant tissue for MALDI-MSI analysis is that the high water content of plant tissue makes it difficult for in situ analysis using MALDI because of the low pressure $\left(10^{-7}\right.$ to $10^{-8}$ Torr) operating conditions. One approach to overcome this issue is by dehydrating the tissue prior to MSI analysis. However, dehydration may lead to disruption of analyte distribution since water loss from the leaf may cause it to shrivel thus altering the original dimensions of the leaf. This obstacle has been overcome in this project by using the printing technique described earlier, because there is no alteration in leaf structure during analyte transfer; therefore, the print of the adaxial side of the geranium leaf onto the MALDI plate results in an accurate representation of the distribution of AnAcs on the tissue.

All plant tissue was analyzed using a Voyager-DE pro MALDI and ion images were constructed using MMSIT. Post-acquisition image analysis was done using TissueView. Figure 23a, is the selected ion image of $\mathrm{m} / \mathrm{z} 374.2$ ([M$\mathrm{H}]^{-}$which corresponds to $24: 1$ w5 AnAcs. This image clearly shows the veins of the geranium leaf. Furthermore, Figure $\mathbf{2 3 b}$ is the digital image of the leaf and the overlay of the digital image and ion image (using InfranView) can be seen in Figure 24c. Because the veins of the leaf protrude from the abaxial surface of the leaf, there was insufficient transfer of AnAcs from the regions of the leaf between the veins, which is why ion images of the abaxial surface of the leaf mainly represent the topology of the leaf's vascular system. However, Figure 24 below shows the ion image of $24: 1^{\omega 5}$ AnAcs from the adaxial surface of the leaf 
a.

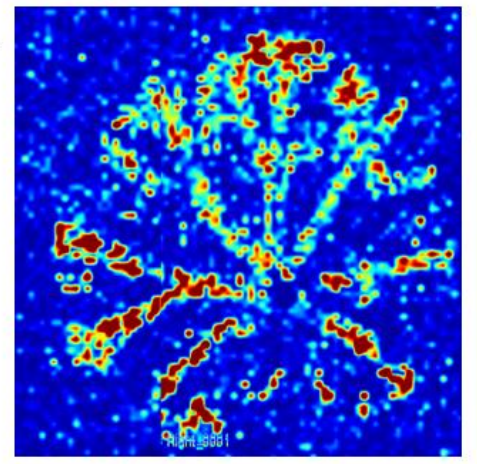

b.

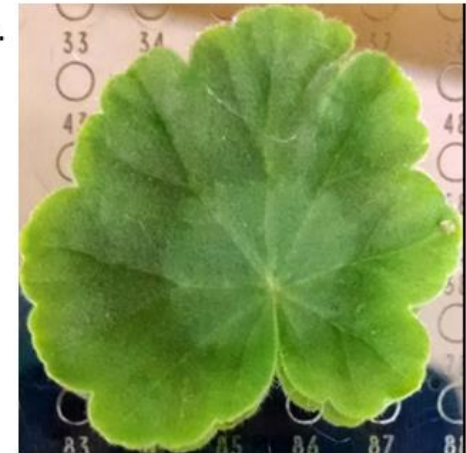

c.

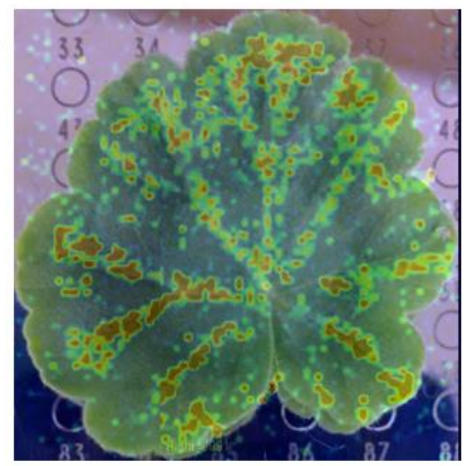

Figure 23: (a) lon image of $\mathrm{m} / \mathrm{z} 374.27$ corresponding to AnAc 24:1 ${ }^{\omega 5}$. (b) Digital image of the leaf that was pressed to generate ion image in "a". (c) Overlay of "a" and "b". 


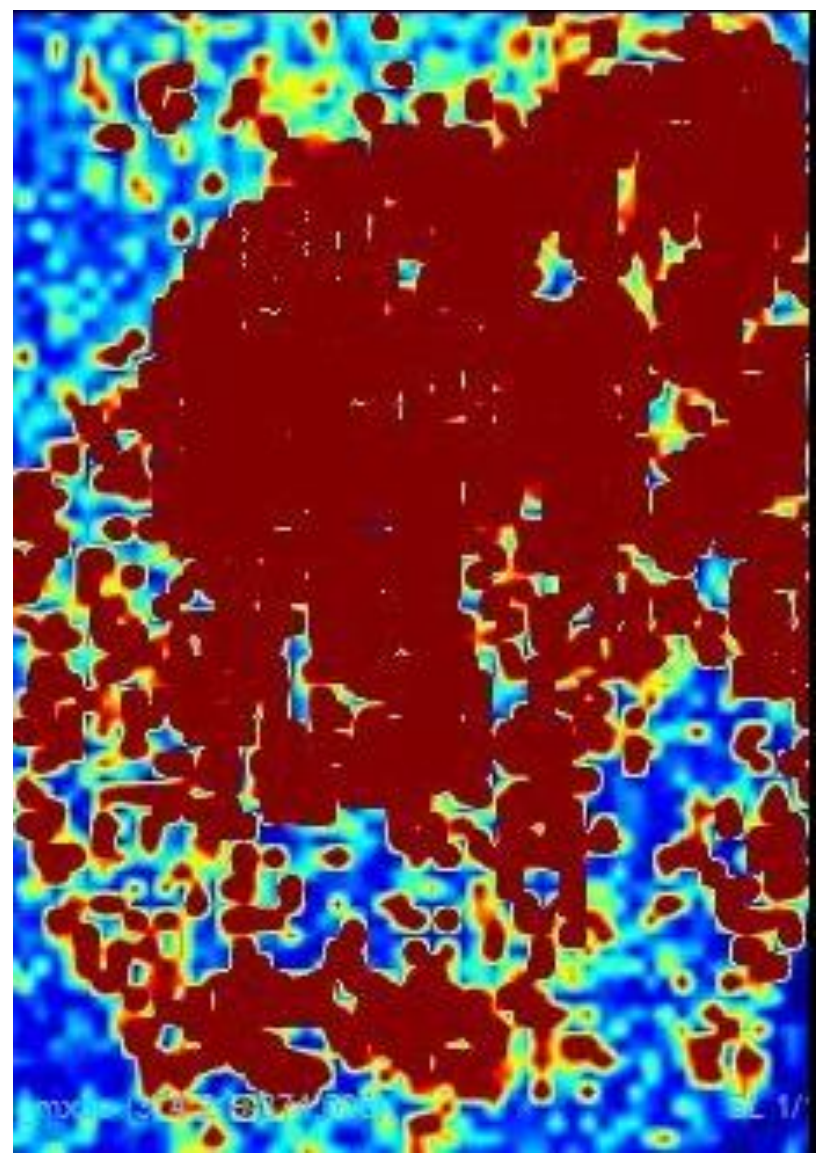

Figure 24: Ion image obtained from the adaxial surface of the leaf at $\mathrm{m} / \mathrm{z}=374.2$ corresponding to AnAc 24:1 ${ }^{\omega 5}$ 
which is more representative of the actual AnAc distribution because of its flatness. In situ analysis of leaves by MALDI-MSI also revealed differences in AnAcs profiles between different geranium species. A blind MSI study was conducted using freshly cut leaves from two different geranium species and the results can be seen in Figure $\mathbf{2 5}$ below. Selected ion images reveal the abundance of $22: 1^{\omega 5}$ and $24: 1^{\omega 5}$ AnAcs (m/z 346.2 and 374.2 respectively) in unknown 1 but not in unknown 2. Furthermore, selected ion images of $\mathrm{m} / \mathrm{z} 346.2$ and 374.2 reveal an abundance of saturated $22: 1^{\omega 5}$ and $24: 1^{\omega 5}$ AnAcs in unknown 2 but not in unknown 1.

\section{Conclusions}

A direct leaf print technique was developed for the imaging of AnAcs distribution on the surface of geranium leaves using MALDI-MSI. In addition to using the ion images to examine the distribution and chemical differences of AnAcs, the ability to acquire these images would also be useful in determining the effects of gene silencing on AnAcs in geranium plants. Furthermore, this technique could be applied to study surface metabolite phenotypes of different plant species. Lastly, MALDI-MSI was successfully used for the differentiation of geranium plants based on their AnAcs profiles. Although the exact species of the geranium could not be determined using the ion images, this could be possible with the discovery of more surface metabolite markers unique for each species. The next stage of this project would involve gene knockdown of metabolic enzymes to determine their role in the production of AnAcs in geranium plants. With this knowledge, scientist could uncover more details about the pathway of 

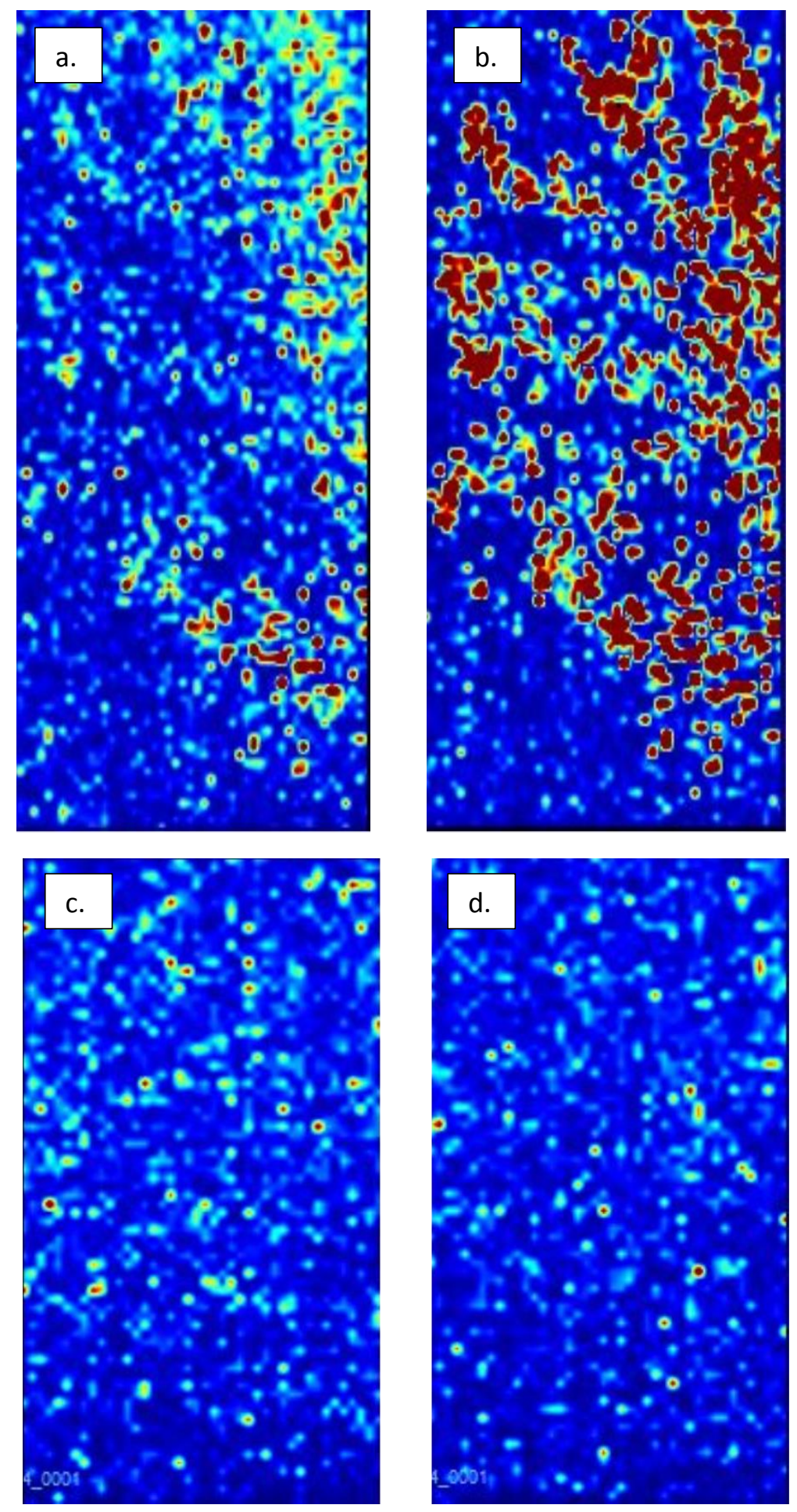

Figure 25: (a) lon images $\left(\mathrm{m} / \mathrm{z}=346.2,22: 1^{\omega 5}\right)$ from non-susceptible geranium. (b) Ion image $\left(\mathrm{m} / \mathrm{z}=374.2,24: 1^{\omega 5}\right)$ from typical non-susceptible geranium. (c) Ion image $\left(\mathrm{m} / \mathrm{z}=346.2,22: 1^{\omega 5}\right)$ from susceptible geranium. (d) lon image $(\mathrm{m} / \mathrm{z}=$ $\left.24: 1^{\omega 5}\right)$ from susceptible geranium. 
AnAcs synthesis and which could contribute to making AnAcs more readily available for therapeutic purposes. 


\section{CHAPTER 3}

\section{Overall Conclusions}

This thesis presents the in-situ imaging of AnAcs, accomplished for the first time using MALDI-MS. Furthermore, this thesis also details the first attempts of in situ imaging of AnAcs via molecular fluorescence (FL). Although FL detection of AnAcs could be done, the data suggest that AnAcs would not be ideal targets for fluorescence imaging since their absorption and emission spectra overlap with those of other cellular components. Today, fluorophores that absorb radiation in the near infrared $(\mathrm{NIR})$ region of the electromagnetic spectrum are becoming more popular since there is less absorption and scattering due to tissue and cellular contents. Consequently, the radiation can penetrate to greater tissue depths.

As mentioned in chapter one, a homogenous matrix distribution is a key factor for the success of MALDI-MSI. To test the homogeneity of the matrix coating using the plate dipping method described in chapter two, the matrix intensity for twenty random locations outside the plant region were compared to twenty random locations within the region where the leaf was pressed. The average intensity inside versus outside were both $3.2 \times 10^{4} \pm 0.3 \times 10^{4}$, not significantly different $(P=0.41)$ using the Student's t-test. This suggests that dipping the plate does result in a homogenous matrix coating. In order to 
determine if the intensity of the $\mathrm{m} / \mathrm{z} 374.2$ band due to AnAc $24: 1$ was significantly higher inside the plant region compared with outside the plant region, the peak intensities from twenty randomly selected locations inside and outside of the plant region were compared. Outside the region where the plant leaf was pressed, the intensity for $\mathrm{m} / \mathrm{z} 374.2$ was within the baseline. However, in the region where the leaf was pressed onto the MALDI plate, the average peak intensity for $\mathrm{m} / \mathrm{z} 374.2$ was $7.29 \times 10^{3} \pm 0.4 \times 10^{4}$. The difference between the mean values outside and inside the pressed region was statistically significant ( $P$ $\left.=7 \times 10^{-10}\right)$ using the Student's t-test. These results confirm the idea that MALDI-MSI can be used to map the spatial distribution of AnAc. Furthermore, since the matrix is homogenous, even in regions where AnAc is present, the matrix peak can be used as an internal standard. Ideally, it would be advantageous to identify other surface compounds on the geraniums leaves so they could be used in comparison with AnAcs.

MALDI-MSI was successful in imaging AnAcs on the surface of geranium leaves using a leaf printing method. Furthermore, MALDI-MSI was successful in analyzing the spatial distribution of AnAcs (mainly $24: 1^{\omega 5}$ and $22: 1^{\omega 5}$ ) in wild type Pelargonium $\times$ hortorum. Since the effects of RNAi silencing are unknown, these images could be used for comparison between wild type and silenced plants. Also, this work represents the first use of bis(p-nitrophenyl) amine (BNPA) as a MALDI matrix. Although BNPA works as a good matrix for the detection of AnAcs, the use of BNPA with other substrates such as peptides, proteins and nucleic acids still needs to be investigated. The use of BNPA was not useful for 
the detection of phosphatidylcholine because it led to a significant cleavage of the phosphocholine head group as seen by presence of a prominent peak at $\mathrm{m} / \mathrm{z}$ 184. The basic nature of BNPA makes it well suited for the negative mode and may also be the factor causing head group loss in phosphatidylcholine.

Unlike FL, in-situ MALDI-MSI was successful in differentiating between different AnAcs and, importantly, it was able to distinguish between two types of geranium plants. While at this time the actual geranium species cannot be identified from the imaging of AnAcs alone, the simultaneous imaging of other species, could enable species differentiation and identification.

\section{Future Directions}

\section{Future Analytical Studies}

One disadvantage of traditional MALDI is that the ionization takes place in a low pressure chamber $\left(10^{-7}-10^{-8}\right.$ Torr). Since plant tissue contains significant amounts of water, a drying step would be necessary before any analysis of tissue. However, atmospheric pressure MALDI (AP-MALDI) would make it possible to image plant tissue directly without the need for drying or using a printing method as described in this thesis. Furthermore, AP-MALDI would open the door for the use of matrices that sublime under low pressure, such as PNA. For example, Steven et al. demonstrated the ability to image lipids using PNA and an intermediate pressure ( 1 Torr) MALDI (62). The group reported that PNA was stable for over a 6-hour time period. 
Although this work has not attempted to quantify the absolute amount of AnAcs on the surface of geranium plants, relative quantification can be done simply by direct comparison of relative intensities of AnAcs expressed on the surface of the leaf. It is expected that the benzene portion of AnAcs is the major contributor to the ionization in MALDI-MS, thus it would be expected that AnAcs and salicylic acid would have a very similar ionization efficiency which would make direct quantification of AnAcs possible by the use of salicylic acid as an internal standard.

\section{Future Biological Studies}

As stated earlier in the thesis, the enzymes responsible for the synthesis of AnAcs remain to be identified. Specifically, the steps that lead to the cyclization of a growing fatty acid chain to form a hydrocarbon tail attached to a carboxylated benzene ring are still unclear. Three condensing enzymes, 3ketoacycl-ACP synthases (KAS), 3-ketoacyl-CoA synthases (KCS), and polyketide synthases (PKS) were all investigated as possible enzymes responsible for condensation/formation of AnAcs from long chain fatty acid precursors. Currently, KASs have been ruled out thus leaving only KCS and

PKS as possible enzymes. A few suspect enzymes from each of the remaining classes have been identified but no work has provided definitive proof as to the identification of the enzyme responsible for AnAc condensation. In the future, conclusive proof could be obtained using gene silencing via ribose nucleic acid interference (RNAi). The hypothesis is that silencing of an enzyme responsible 
for AnAcs production would lead to a decrease in AnAcs secretion which could be visualized using the MALDI-MSI technique described in chapter 2 .

Lastly, aside from using MALDI-MSI to detect gene silencing in geranium plants, MALDI-MSI could be used to investigate AnAcs uptake by breast cells. Researchers could use MADLI-MSI to determine the amount of AnAc uptake in breast cancer cells in patients undergoing AnAc therapy. 


\section{REFERENCES}

Aerni, H. R., Cornett, D. S., \& Caprioli, R. M. (2006). Automated acoustic matrix deposition for MALDI sample preparation. Anal Chem, 78(3), 827-834. doi: 10.1021/ac051534r

Allwood, D. A., Dyer, P. E., Dreyfus, R. W., \& Perera, I. K. (1997). Plasma modelling of matrix assisted UV laser desorption ionisation (MALDI). Applied Surface Science, 109, 616-620. doi: 10.1016/s01694332(96)00643-5

Amstalden van Hove, E. R., Smith, D. F., \& Heeren, R. M. (2010). A concise review of mass spectrometry imaging. J Chromatogr A, 1217(25), 39463954. doi: 10.1016/j.chroma.2010.01.033

Astigarraga, E., Barreda-Gomez, G., Lombardero, L., Fresnedo, O., Castano, F., Giralt, M. T., ... Fernandez, J. A. (2008). Profiling and Imaging of Lipids on Brain and Liver Tissue by Matrix-Assisted Laser Desorption/lonization Mass Spectrometry Using 2-Mercaptobenzothiazole as a Matrix. Anal Chem, 80(23), 9105-9114. doi: 10.1021/ac801662n

Balick, M. J. E. E. L. S. A. P. D. (1996). Medicinal Resources of the Tropical Forest: Biodiversity and Its Importance to Human Health. Nature., 382(6590), 412.

Baluya, D. L., Garrett, T. J., \& Yost, R. A. (2007). Automated MALDI matrix deposition method with inkjet printing for imaging mass spectrometry. Anal Chem, 79(17), 6862-6867. doi: 10.1021/ac070958d

Barker, J., Ando, D. J., \& Davis, R. (1999). Mass spectrometry. New York: John Wiley \& Sons.

Bell, P. Notes on Mass Spectrometry. Retrieved June 15, 2014, from https://facultystaff.richmond.edu/ jbell2/Chemistry-329-mass-spec.htm

Burrell, M., Earnshaw, C., \& Clench, M. (2007). Imaging Matrix Assisted Laser Desorption lonization Mass Spectrometry: a technique to map plant metabolites within tissues at high spatial resolution. J Exp Bot, 58(4), 757763. doi: 10.1093/jxb/erl139

Caprioli, R. M., Farmer, T. B., \& Gile, J. (1997). Molecular imaging of biological samples: Localization of peptides and proteins using MALDI-TOF MS. Anal Chem, 69(23), 4751-4760. doi: 10.1021/ac970888i

Castillo-Juarez, I., Rivero-Cruz, F., Celis, H., \& Romero, I. (2007). AntiHelicobacter pylori activity of anacardic acids from Amphipterygium adstringens. J Ethnopharmacol, 114(1), 72-77. doi: 10.1016/j.jep.2007.07.022

Cesla, P., Blomberg, L., Hamberg, M., \& Jandera, P. (2006). Characterization of anacardic acids by micellar electrokinetic chromatography and mass 
spectrometry. J Chromatogr A, 1115(1-2), 253-259. doi:

10.1016/j.chroma.2006.02.070

Chalfie, M., Tu, Y., Euskirchen, G., Ward, W. W., \& Prasher, D. C. (1994).

GREEN FLUORESCENT PROTEIN AS A MARKER FOR GENE-

EXPRESSION. Science, 263(5148), 802-805. doi:

10.1126/science.8303295

Colsch, B., Jackson, S. N., Dutta, S., \& Woods, A. S. (2011). Molecular microscopy of brain gangliosides: illustrating their distribution in hippocampal cell layers. ACS chemical neuroscience, 2(4), 213-222.

Correa, P., \& Houghton, J. (2007). Carcinogenesis of Helicobacter pylori. Gastroenterology, 133(2), 659-672.

Dixon, M. (2001). Pathology of gastritis and peptic ulceration.

Estrada, R., \& Yappert, M. C. (2004). Regional phospholipid analysis of porcine lens membranes by matrix-assisted laser desorption/ionization time-offlight mass spectrometry. J Mass Spectrom, 39(12), 1531-1540. doi: $10.1002 / \mathrm{jms} .759$

Farnsworth, N. R., Akerele, O., Bingel, A. S., Soejarto, D. D., \& Guo, Z. (1986). THE ROLE OF MEDICINAL-PLANTS IN THERAPY. Bulletin of the World Health Organization, 64(2), 159-175.

Fernandez, J. A., Ochoa, B., Fresnedo, O., Giralt, M. T., \& Rodriguez-Puertas, R. (2011). Matrix-assisted laser desorption ionization imaging mass spectrometry in lipidomics. Anal Bioanal Chem, 401(1), 29-51. doi: 10.1007/s00216-011-4696-x

Fitzgerald, M. C., Parr, G. R., \& Smith, L. M. (1993). BASIC MATRICES FOR THE MATRIX-ASSISTED LASER-DESORPTION IONIZATION MASSSPECTROMETRY OF PROTEINS AND OLIGONUCLEOTIDES. Anal Chem, 65(22), 3204-3211. doi: 10.1021/ac00070a007

Garden, R. W., \& Sweedler, J. V. (2000). Heterogeneity within MALDI samples as revealed by mass spectrometric imaging. Anal Chem, 72(1), 30-36. doi: 10.1021/ac9908997

Gellerman, J. L., \& Schlenk, H. (1968). Methods for isolation and determination of anacardic acids. Anal Chem, 40(4), 739-743.

Gerhold, D. L., Craig, R., \& Mumma, R. O. (1984). Analysis of trichome exudate from mite-resistant geraniums. Journal of chemical ecology, 10(5), 713722.

Gode, D., \& Volmer, D. A. (2013). Lipid imaging by mass spectrometry-a review. Analyst, 138(5), 1289-1315.

Gusev, A. I., Vasseur, O. J., Proctor, A., Sharkey, A. G., \& Hercules, D. M. (1995). IMAGING OF THIN-LAYER CHROMATOGRAMS USING MATRIX/ASSISTED LASER DESORPTION/IONIZATION MASSSPECTROMETRY. Anal Chem, 67(24), 4565-4570. doi: 10.1021/ac00120a021

Hamm, G., Carre, V., Poutaraud, A., Maunit, B., Frache, G., Merdinoglu, D., \& Muller, J. F. (2010). Determination and imaging of metabolites from Vitis vinifera leaves by laser desorption/ionisation time-of-flight mass 
spectrometry. Rapid Commun Mass Spectrom, 24(3), 335-342. doi: 10.1002/rcm.4395

Hankin, J. A., Barkley, R. M., \& Murphy, R. C. (2007). Sublimation as a method of matrix application for mass spectrometric imaging. J Am Soc Mass Spectrom, 18(9), 1646-1652. doi: 10.1016/j.jasms.2007.06.010

Hemker, H. C., \& van Dam-Mieras, M. C. E. (1983). Handbook of Synthetic Substrates: For the coagulation and fibrinolytic system: Springer Science \& Business Media.

Hillenkamp, F., Jaskolla, T. W., \& Karas, M. (2014). The MALDI Process and Method.

Hintersteiner, M., Enz, A., Frey, P., Jaton, A. L., Kinzy, W., Kneuer, R., . . . Gremlich, H. U. (2005). In vivo detection of amyloid-beta deposits by nearinfrared imaging using an oxazine-derivative probe. Nat Biotechnol, 23(5), 577-583. doi: $10.1038 / \mathrm{nbt} 1085$

Hsieh, Y., Chen, J., \& Korfmacher, W. A. (2007). Mapping pharmaceuticals in tissues using MALDI imaging mass spectrometry. J Pharmacol Toxicol Methods, 55(2), 193-200. doi: 10.1016/j.vascn.2006.06.004

Ingle Jr, J. D., \& Crouch, S. R. (1988). Spectrochemical analysis.

ISS | Technical Notes | Fluorescence Lifetime. (2015). from http://www.iss.com/resources/research/technical notes/K2CH FLT.html

Karas, M., Bachmann, D., \& Hillenkamp, F. (1985). INFLUENCE OF THE WAVELENGTH IN HIGH-IRRADIANCE ULTRAVIOLET-LASER DESORPTION MASS-SPECTROMETRY OF ORGANIC-MOLECULES. Anal Chem, 57(14), 2935-2939. doi: 10.1021/ac00291a042

Karas, M., Gluckmann, M., \& Schafer, J. (2000). Ionization in matrix-assisted laser desorption/ionization: singly charged molecular ions are the lucky survivors. Journal of Mass Spectrometry, 35(1), 1-12. doi: 10.1002/(sici)1096-9888(200001)35:1<1::aid-jms904>3.0.co;2-0

Karas, M., \& Hillenkamp, F. (1988). LASER DESORPTION IONIZATION OF PROTEINS WITH MOLECULAR MASSES EXCEEDING 10000 DALTONS. Anal Chem, 60(20), 2299-2301. doi: 10.1021/ac00171a028

Kokudo, N., \& Ishizawa, T. (2012). Clinical application of fluorescence imaging of liver cancer using indocyanine green. Liver cancer, 1(1), 15.

Krause, J., Stoeckli, M., \& Schlunegger, U. P. (1996). Studies on the selection of new matrices for ultraviolet matrix-assisted laser desorption/ionization time-of-flight mass spectrometry. Rapid Communications in Mass Spectrometry, 10(15), 1927-1933. doi: 10.1002/(sici)10970231(199612)10:15<1927::aid-rcm709>3.0.co;2-v

Lakowicz, J. R. (2007). Principles of fluorescence spectroscopy: Springer Science \& Business Media.

Mahadevappa Hemshekhar, Martin Sebastin Santhosh, Kempaiah Kemparaju, \& Girish, K. S. (2011). Emerging Roles of Anacardic Acid and Its Derivatives A Pharmacological Overview. Basic \& Clinical Pharmacology \& Toxicology. 
Mamyrin, B., Karataev, V., Shmikk, D., \& Zagulin, V. (1973). The massreflect ron, a new non-magnetic time-of-flight mass spectrometer with high resolution. Zh. Eksp. Teor. Fiz, 64, 82-89.

Marto, J. A., White, F. M., Seldomridge, S., \& Marshall, A. G. (1995). STRUCTURAL CHARACTERIZATION OF PHOSPHOLIPIDS BY MATRIX-ASSISTED LASER-DESORPTION IONIZATION FOURIERTRANSFORM ION-CYCLOTRON RESONANCE MASSSPECTROMETRY. Anal Chem, 67(21), 3979-3984. doi: 10.1021/ac00117a025

Montaudo, G., \& Lattimer, R. P. (2010). Mass spectrometry of polymers: CRC Press.

Montet, X., Rajopadhye, M., \& Weissleder, R. (2006). An albumin-activated farred fluorochrome for in vivo imaging. ChemMedChem, 1(1), 66-69. doi: $10.1002 / \mathrm{cmdc} .200500028$

Mullen, A. K., Clench, M. R., Crosland, S., \& Sharples, K. R. (2005). Determination of agrochemical compounds in soya plants by imaging matrix-assisted laser desorption/ionisation mass spectrometry. Rapid Commun Mass Spectrom, 19(18), 2507-2516. doi: 10.1002/rcm.2078

Newman, D. J., Cragg, G. M., \& Snader, K. M. (2000). The influence of natural products upon drug discovery (Antiquity to late 1999). Natural Product Reports, 17(3), 215-234. doi: 10.1039/a902202c

Olympus Microscopy Resource Center | Jablonski Energy Diagram - Java Tutorial. (2015). from http://www.olympusmicro.com/primer/java/jablonski/jabintro/

Ramanujam, N. (2006). Fluorescence Spectroscopy In Vivo Encyclopedia of Analytical Chemistry: John Wiley \& Sons, Ltd.

Rao, J., Dragulescu-Andrasi, A., \& Yao, H. (2007). Fluorescence imaging in vivo: recent advances. Curr Opin Biotechnol, 18(1), 17-25. doi:

10.1016/j.copbio.2007.01.003

Rezaei, B., Havakeshian, E., \& Ensafi, A. A. (2013). Stainless steel modified with an aminosilane layer and gold nanoparticles as a novel disposable substrate for impedimetric immunosensors. Biosens Bioelectron, 48, 6166. doi: 10.1016/j.bios.2013.03.061

Rujoi, M., Estrada, R., \& Yappert, M. C. (2004). In situ MALDI-TOF MS regional analysis of neutral phospholipids in lens tissue. Anal Chem, 76(6), 16571663. doi: $10.1021 / \mathrm{ac} 0349680$

Salih, B., \& Zenobi, R. (1998). MALDI mass spectrometry of dye-peptide and dye-protein complexes. Anal Chem, 70(8), 1536-1543. doi: 10.1021/ac9708506

Schultz, D. J., Cahoon, E. B., Shanklin, J., Craig, R., Cox-Foster, D. L., Mumma, R. O., \& Medford, J. I. (1996). Expression of a delta 9 14: 0-acyl carrier protein fatty acid desaturase gene is necessary for the production of omega 5 anacardic acids found in pest-resistant geranium (Pelargonium $\mathrm{x}$ hortorum). Proceedings of the National Academy of Sciences, 93(16), 8771-8775. 
Schultz, D. J., Olsen, C., Cobbs, G. A., Stolowich, N. J., \& Parrott, M. M. (2006). Bioactivity of anacardic acid against Colorado potato beetle (Leptinotarsa decemlineata) larvae. Journal of Agricultural and Food Chemistry, 54(20), 7522-7529. doi: 10.1021/jf061481u

Schultz, D. J., Wickramasinghe, N. S., Ivanova, M. M., Isaacs, S. M., Dougherty, S. M., Imbert-Fernandez, Y., . . Klinge, C. M. (2010). Anacardic acid inhibits estrogen receptor alpha-DNA binding and reduces target gene transcription and breast cancer cell proliferation. Mol Cancer Ther, 9(3), 594-605. doi: 10.1158/1535-7163.MCT-09-0978

Schwartz, S. A., Reyzer, M. L., \& Caprioli, R. M. (2003). Direct tissue analysis using matrix-assisted laser desorption/ionization mass spectrometry: practical aspects of sample preparation. J Mass Spectrom, 38(7), 699708. doi: 10.1002/jms.505

Sharma, A., \& Schulman, S. G. (1999). Introduction to fluorescence spectroscopy (Vol. 13): Wiley-Interscience.

Smith, R. M., \& Busch, K. L. (1999). Understanding mass spectra : a basic approach. New York: Wiley.

So, M. K., Xu, C., Loening, A. M., Gambhir, S. S., \& Rao, J. (2006). Selfilluminating quantum dot conjugates for in vivo imaging. Nat Biotechnol, 24(3), 339-343. doi: 10.1038/nbt1188

Solon, E. G., Schweitzer, A., Stoeckli, M., \& Prideaux, B. (2010). Autoradiography, MALDI-MS, and SIMS-MS imaging in pharmaceutical discovery and development. AAPS J, 12(1), 11-26. doi: 10.1208/s12248009-9158-4

Spengler, B., \& Hubert, M. (2002). Scanning microprobe matrix-assisted laser desorption ionization (SMALDI) mass spectrometry: Instrumentation for sub-micrometer resolved LDI and MALDI surface analysis. J Am Soc Mass Spectrom, 13(6), 735-748. doi: 10.1016/s1044-0305(02)00376-8

Stoeckli, M., Staab, D., \& Schweitzer, A. (2007). Compound and metabolite distribution measured by MALDI mass spectrometric imaging in wholebody tissue sections. International Journal of Mass Spectrometry, 260(23), 195-202. doi: 10.1016/j.jims.2006.10.007

Trimpin, S., Inutan, E. D., Herath, T. N., \& McEwen, C. N. (2010). Matrix-assisted laser desorption/ionization mass spectrometry method for selectively producing either singly or multiply charged molecular ions. Anal Chem, 82(1), 11-15. doi: 10.1021/ac902066s

Viswanadham, S. K., Hercules, D. M., Schreiber, E. M., Weller, R. R., \& Giam, C. S. (1988). ION-MOLECULE REACTIONS IN THE NEGATIVE-ION LASER MASS-SPECTRA OF AROMATIC NITRO-COMPOUNDS. Anal Chem, 60(21), 2346-2353. doi: 10.1021/ac00172a007

Wang, H. Y., Jackson, S. N., \& Woods, A. S. (2007). Direct MALDI-MS analysis of cardiolipin from rat organs sections. J Am Soc Mass Spectrom, 18(3), 567-577. doi: 10.1016/j.jasms.2006.10.023

Wang, X. F., \& Herman, B. (1996). Fluorescence imaging spectroscopy and microscopy: Wiley. 
Watrous, J. D., \& Dorrestein, P. C. (2011). Imaging mass spectrometry in microbiology. Nat Rev Microbiol, 9(9), 683-694. doi: 10.1038/nrmicro2634

Zenobi, R., \& Knochenmuss, R. (1998). Ion formation in MALDI mass spectrometry. Mass Spectrometry Reviews, 17(5), 337-366. doi: 10.1002/(sici)1098-2787(1998)17:5<337::aid-mas2>3.0.co;2-s

Zhang, H., Cha, S. W., \& Yeung, E. S. (2007). Colloidal graphite-assisted laser desorption/ionization MS and MSn of small molecules. 2. Direct profiling and MS imaging of small metabolites from fruits. Anal Chem, 79(17), 6575-6584. doi: 10.1021/ac0706170 


\title{
CURRICULUM VITAE
}

\section{Bryan Wessel}

\author{
University of Louisville School of Medicine
}

Name: Bryan Wessel, M.S., M.B.A

Address

4413 Santa Paula Ln.

U.S.A.

Louisville KY 40219 U.S.A.

Phones

Cell: (859) 630-7343

E-mail: b0wess01@louisville.edu
Birth date: $\quad$ July 16, 1989

Birth Place: $\quad$ Ft. Thomas, KY

Citizenship: $\quad$ United States

Marital Status: $\quad$ Married

Number of Children: Zero

\section{A. Education}

University of Louisville, Louisville, Kentucky, B.S. Biology 2011

University of Louisville, Louisville, Kentucky, M.S. Chemistry (Analytical) 2015

University of Louisville, Louisville, Kentucky, M.B.A 2015.

\section{B. Academic and Professional Experience}

8/2012-7/2014 Chemistry Teaching Assistant, University of Louisville, Louisville, KY 
1/2009-7/2012 Chemistry, Biology, and Physics Tutor, University of Louisville, Louisville, KY

\section{Military Service None.}

D. Board Certification and Licensure None

E. Professional Societies

American Medical Association

American Chemical Society

Heterocyclic Chemistry Society

F. Awards and Named Lectureships

4/2009 Most Outstanding Junior, University of Louisville

G. Committee Assignments and Administrative Services

None

H. Journal Editorial Boards and Advisory Councils

None

\section{Teaching}

None

\section{J. Abstracts and Presentations}

i) The Importance of siRNA in the Emerging Field of Nanotechnology." University of Louisville, Louisville, Kentucky, November, 2013.

K. Funding

a. Funded Grants 
i) 08/2013-07/2014 PI Yappert, "Imaging of Anacardic Acid on the Surface of Pelargonium $\times$ hortorum" $\$ 500$. Graduate Student Research and Creative Activities Grant, University of Louisville, for Bryan Wessel

\section{b. Pending Grants}

None

\section{Bibliography}

\section{a. Publications}

None 